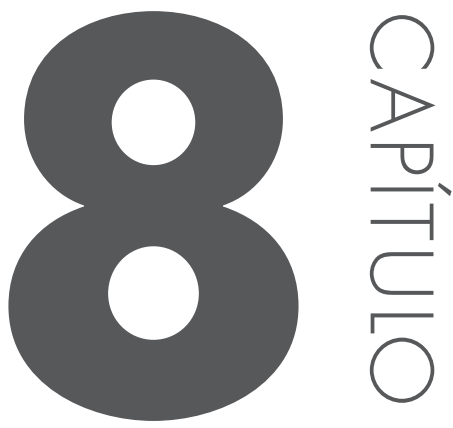

\title{
ALTERAÇÕES DEMOGRÁFICAS DA POPULAĈ̣̃O LOCAL AO LONGO DO DESENVOLVIMENTO DA REGIÃO TURÍSTICA: UM ESTUDO NO MUNICÍPIO DE TIBAU DO SUL (RN)'
}

Nilson Cortez Crocia de Barros

No presente trabalho são identificadas alterações demográficas na população residente no Município de Tibau do Sul acontecidas nos últimos vinte anos, de I990 a 2010 . A população dos turistas ou visitantes (os consumidores) não foi objeto atenção, e sim a população local residente entendida segundo a definição oficial do Instituto Brasileiro de Geografia e Estatística

I Texto originalmente publicado em: BARROS, Nilson Cortez Crocia de. Alterações demográficas da população local ao longo do desenvolvimento da região turística: estudo no município de Tibau do sul, RN, Brasil, I99I-20Io- uma aplicação do método comparativo ao estudo da dinâmica das propriedades geográficas dos lugares. Cadernos de Estudos Sociais, Recife, V.29, n. I, p. 86-I32, jan/jun, 2014. 
(IBGE). O trabalho procura então descrever características demográficas da população local a partir do exame dos dados demográficos - Censos e Contagens oficiais - disponíveis para os anos de I99I, I996, 2000, 2007 e 20IO. Para os anos de 2000 e 2010 , examinaram-se os microdados referentes às migrações.

De forma muito tentativa e flexível, procura-se associar os padrões demográficos identificados nesses anos e as suas alterações ao longo das duas décadas (I990 e 2000), à tipologia das fases de evolução das destinações turísticas envelopada no modelo do ciclo dos resorts de R. Butler (I980). Observo que a tipologia foi adaptada ao estudo da destinação em trabalhos anteriores, de forma mais compreensiva em Barros (2009).

As apreciações das séries das variáveis demográficas escolhidas para o Município de Tibau do Sul, nos decênios indicados, permitiram, de fato, identificar mudanças nos padrões ou perfis indicados nesse município. Não obstante, essas evidências, fruto apenas das comparações entre os instantes (anos de Censos ou Contagens) sucessivos dentro da mesma unidade geográfica de observação - o Município de Tibau do Sul -, optamos pelo artifício da comparação geográfica mediante contrastes, quer dizer, o método de cotejar as mesmas variáveis como expressão de lugares ou regiões divergentes quanto a características geográficas gerais.

Tal artifício produziu melhor figuração e nitidez na identificação das alterações acontecidas na destinação, isto é, no Município de Tibau do Sul. A outra unidade municipal escolhida para ser comparada, no mesmo período e com base nas mesmas variáveis, foi o Município de Espírito Santo, também no Estado do Rio Grande do Norte. Essa unidade municipal não foi afetada por nenhuma dinâmica econômica local diferenciadora durante o período e, nos anos de 1980 e antes, os dois municípios (ou regiões político-administrativas) poderiam ser francamente equalizados como domínios territoriais tradicionais.

No presente trabalho, após breve apresentação da área de pesquisa - o que inclui descrever as condições sociais e ambientais prévias e contemporâneas à difusão, cuja exposição é necessária ao melhor entendimento contextual das alterações demográficas que tiveram lugar nos últimos vinte anos -, procede-se à revisão da literatura dedicada ao modelo de ciclo dos resorts, que é a teoria regional envolvente do trabalho. Em continuação, faz-se revisão das discussões demográficas pertinentes ao caráter das populações residentes em domínios territoriais de desenvolvimento turístico. Depois, examina-se empiricamente a dinâmica demográfica da população residente no Município de Tibau do Sul pelo método comparativo, e oferecem-se as conclusões. 
$\mathrm{Na}$ parte empírica, estão descritas as características demográficas da população da unidade municipal (Tibau do Sul) a partir dos dados populacionais oficiais disponíveis para os anos censitários e de contagens significativos ao objetivo da pesquisa. Os dados da dinâmica da função (hospedagem) permitiram construir a série histórica da oferta de meios de hospedagem (Unidades de Habitação, UHs em hotéis/pousadas), de forma contínua desde I 990 até o ano de 2005 , e incluiu-se o ano de 20 I I, restando a lacuna de dados para o intervalo 2006-2010, para o Município de Tibau do Sul, a destinação turística (Gráfico I). Como o objetivo da pesquisa é teórico - especificamente proceder à exploração das relações de influência entre o desenvolvimento turístico e as alterações demográficas, visando identificação e confirmação de tendências -, os dados de hospedagem contínuos até 2005 , e incluindo-se na série os disponíveis para o ano de 20 I I, permitem sem dúvida discutir as alterações demográficas tendo como pano de fundo o desenvolvimento turístico expresso pela série de Unidades de Habitação, até a fase de consolidação ( 4 fases), para empregar a linguagem do modelo de ciclo referido.

Os dados contínuos referentes aos meios de hospedagem foram sendo analisados e discutidos na perspectiva da teoria do ciclo progressivamente (Barros, 2002 a b, 2003, 2005, 2009). Reconhecemos que o período coberto pela série dos meios de hospedagem é suficientemente longo para incluir sintomas de pelo menos quatro fases (exploração, envolvimento, desenvolvimento e consolidação) do conjunto das seis propostas pelo modelo teórico ou ideal do ciclo de R. Butler, exceto naturalmente as duas últimas (estagnação, declínio), não obstante o caráter polêmico que toda apreciação referente ao posicionamento dos resorts dentro do ciclo apresenta, como se verá na revisão teórica.

Com base nas pesquisas anteriores, já citadas, sugiro que Pipa - que é a vila turística core dentro do Município de Tibau do Sul - estaria experimentando uma espécie de prolongamento das características da fase de desenvolvimento (Barros, 2009), o que se confirma com os dados de hospedagem disponíveis para o ano de 20 I I. Esta fase apresenta, em função da persistência da demanda turística e da grande oferta de capital natural, uma curiosa situação de overlapping (superposição) com a teoricamente posterior fase de consolidação da destinação. O prolongamento teria a propriedade de retardar as fases da estagnação e do declínio - etapas ou fases posteriores na sequência teórica -, elastecendo deste modo o ciclo do produto turístico, ou seja, prolongando o ciclo de vida da região turística em estudo. 


\section{O TURISMO NO MUNICÍPIO DE TIBAU DO SUL}

A difusão do turismo no Município de Tibau do Sul, Estado do Rio Grande do Norte, seguiu o padrão conhecido como SSS - Sun, sand and sea - dominante no Nordeste do Brasil. Tibau é, como destinação, uma das diversas centralidades a partir das quais se realizou a difusão da urbanização de padrão turístico nestas fronteiras de serviços litorâneas. Tal expansão do turismo fez com que, por sobre áreas antes de escassa utilização produtiva, acontecesse a expansão da fronteira dos serviços de lazer, entretenimento e acomodações. Ao longo do litoral existiam, e existem ainda, consideráveis secções de área que exibem notáveis estoques de capital natural, zonas que se tem transformado em fronteiras de recursos de interesse aos empreendedores do setor turístico. Então, não obstante peculiaridades, o desenvolvimento do turismo no Município de Tibau do Sul (Figura I) ostenta traços comuns às destinações litorâneas no Nordeste do Brasil, particularmente àquelas localidades de desenvolvimento mais "espontâneo".

Figura 1

Regiăo Turística de Pipa - RTP

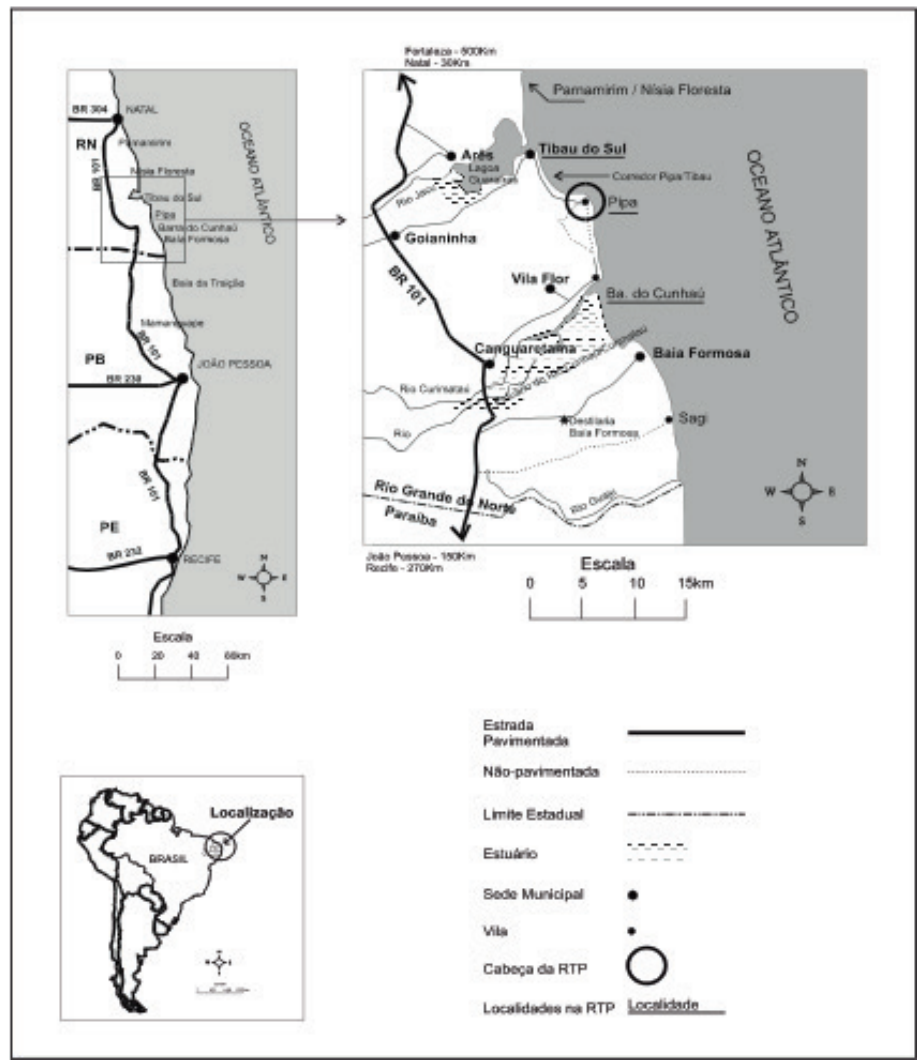


Gráfico 1

Tíbau do Sul: Unidades de Habitação

fontes: Pesquisa direta.PMT do Sul.lbge (2011)

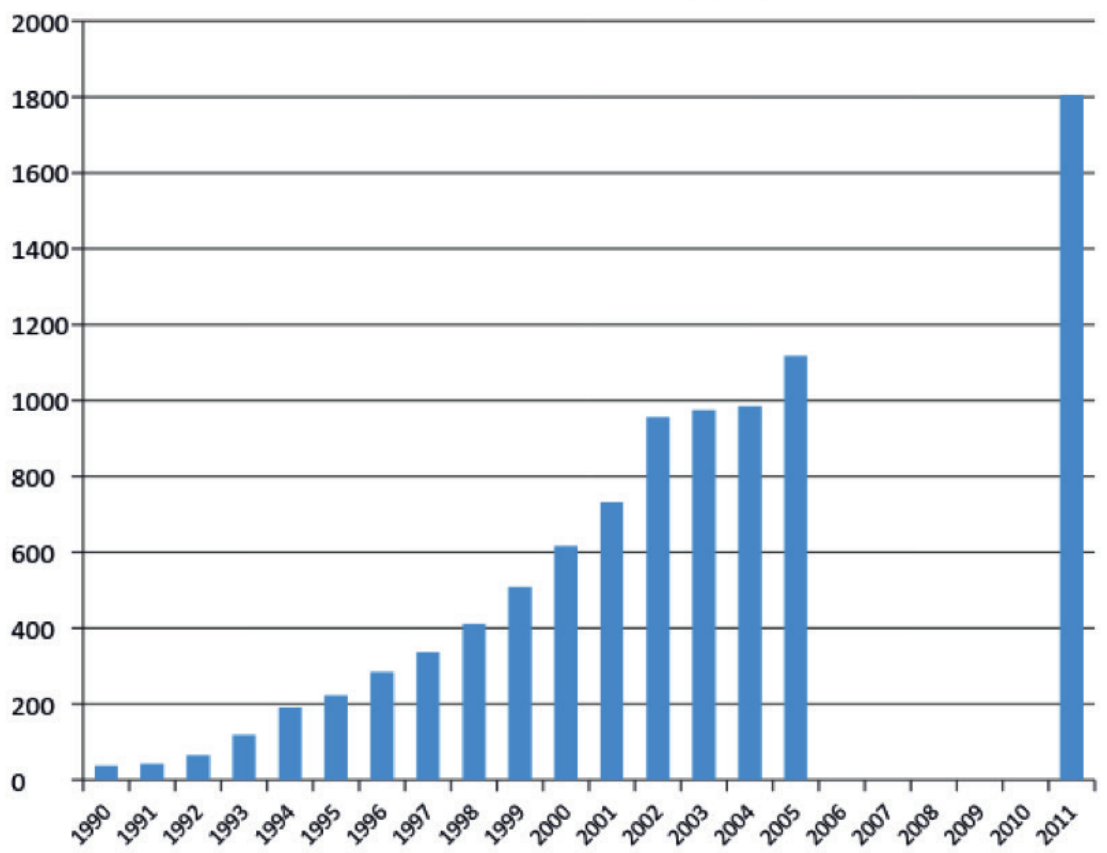

\section{As condições sociais e territoriais em Tibau do Sul pré-difusão turística}

Os assentamentos de população que hoje são destinações turísticas no âmbito do Município de Tibau do Sul, isto é, a sede do Município de Tibau do Sul e a vila de Pipa, possuem origens que remontam ao período colonial, posto que foram registrados pelo cronista Aires do Casal no começo do século I9 na sua obra Corografia Brasílica (I 8I7) (Casal, I976, p.278-279). Aqueles povoados eram pequenos portos pesqueiros articulados funcionalmente ao mundo dos engenhos da várzea do rio Jacu - cujo centro era a povoação de Goianinha - ou da várzea do rio Curimataú (povoações de Vila Flor e Canguaretama), ligando-se a estes núcleos pelos rios mencionados ou mediante caminhos carroçáveis, sistema de povoamento - habitat, especificamente - descrito classicamente por Melo (1958, p.225-228), Andrade (I957, p.II-30), Andrade (I959) (Figura I). 
Bem mais tarde, foram os usineiros e senhores de engenho, entre outros influentes, os primeiros a utilizarem estes vilarejos como balneários, a partir dos anos de I930, sem que tal utilização removesse destas localidades praieiras suas herdadas características rurais e pesqueiras. O fato é que Tibau do Sul e a sua vila de Pipa, por falta de volume na demanda local por turismo, nunca se constituíram em destinações turísticas de massa, mas sim destinações restritas às poucas famílias da elite agrária, burocrática e comerciante da hinterlândia canavieira, algodoeira e pecuária mais próxima. Pousadas nunca se desenvolveram na área, exceto a partir dos anos de I990, data que é aqui tomada como o início do ciclo da destinação.

Tabela 1 - Tibau do Sul, RN. População residente e taxas de crescimento médio geom. anual, 1991-2010

\begin{tabular}{lcccccccccc}
\hline MUNICÍPIO & \multicolumn{3}{c}{ POPULAC̄AO RESIDENTE } & \multicolumn{6}{c}{ TAXA DE CRESCIMENTO GEOMÉTRICO ANUAL (ANOS) (\%) } \\
\hline & 1991 & 1996 & 2000 & 2007 & 2010 & $1991 / 96$ & $1996 / 00$ & $2000 / 7$ & $2007 / 10$ \\
\hline Tibau do Sul & 5.964 & 5.946 & 7.757 & 10.950 & 11.385 & $-0,05$ & 6,80 & 5,08 & 1,28 \\
\hline
\end{tabular}

Fontes: IBGE (1996, 2007), Contagem de população. Rio de Janeiro.

IBGE (1991, 2000, 2010), Censos demográficos. Rio de Janeiro.

Num sentido mais amplo, não aconteceram, apesar do desenvolvimento turístico, alterações profundas na estrutura mais geral da distribuição da população nesta área, mas sim o reforço ou maior concentração do povoamento em algumas secções territoriais em Tibau do Sul. Mas a população cresceu significativamente nas duas últimas décadas, isto em boa medida impulsionada pelo turismo, mas seguindo no geral uma estrutura de circulação e distribuição populacional herdada do período colonial. Em decorrência da demanda pela destinação, a partir dos anos de I990 os caminhos carroçáveis coloniais foram sendo revestidos por asfalto, o que atraiu novos consumidores turísticos, facilitando-se a difusão do turismo de casas de fins de semana e principalmente do turismo hoteleiro, assim como as visitas de um dia. Este é, realmente, o começo da difusão do turismo no litoral do Município de Tibau do Sul, vila de Pipa. 


\section{O turismo e a sua regionalização no Município de Tibau do Sul}

Foi o litoral municipal o campo da difusão turística. Neste litoral podem ser identificados, numa análise morfofuncional, quatro focos da dinâmica territorial dos investimentos do setor. Estes focos de investimentos representam aqui também os elementos da estrutura espacial da Região Turística em consideração e estão identificados abaixo (Quadro I).

Quadro 1 - Elementos espaciais do assentamento turístico em Tibau do Sul

\section{A sede administrativa de Tibau do Sul.}

2. 0 Corredor de hotéis que se estende desde a Sede de Tibau até à vila de Pipa.

\section{A Zona Central da vila de Pipa.}

4. A Periferia ou Bordas imediatas à vila de Pipa, área de expansão em função do congestionamento da Zona Central da vila.

Fonte: Barros, 2009.

A expansão do turismo e o crescimento da população foram extraordinários em Tibau do Sul, particularmente na vila de Pipa, desde os meados dos anos de I990 até meados da década passada (Tabela I). Foi a fase do grande desenvolvimento da destinação, fase que parece ter dado lugar nos últimos anos à de consolidação, ou melhor, dado lugar a uma complexa situação de mistura de caracteres das duas fases mencionadas (desenvolvimento e consolidação). Decorrentes do crescimento foram, entre outros fatos, a elevação do preço da terra na vila de Pipa e a crescente densidade das edificações. Essa valorização da terra reverberou para todo o Município de Tibau, inclusive secções rurais. Os congestionamentos de circulação na Zona Central da vila de Pipa (elemento 3, Quadro I) se tornaram grande problema-reflexo desta densidade, levando à construção, com recursos do PRODETUR II, do Anel Viário de Pipa (BNB.PRODETUR, 20I2).

Resultado é que a sede de Tibau do Sul (elemento I, Quadro I), o mencionado Corredor Tibau-Pipa (elemento 2) e as Bordas e Periferias da vila de Pipa (elemento 4) representam as unidades territoriais de especial interesse para os investidores com objetivos de instalar hotéis do padrão resort ou não (Figura I). Para os hóspedes das outras unidades territoriais do assentamento, a Zona Central da vila de Pipa tornou-se progressivamente a área de visitação com fins de gastronomia, compras e diversão noturna, espécie de 
DCN (Distrito Central de Negócios) da Região Turística em foco como um todo, verificando-se uma divisão territorial-funcional nos serviços. Há claros incrementos de capital cultural na área, e de perdas de capital natural, para empregar a imagem do balanço de capitais (GARROD-FYALL, I998). Estas observações sugerem sinais da fase de consolidação.

Como antes indicado, a destinação teria entrado numa fase de consolidação, não obstante pessimistas indiquem preocupantes sinais - ainda que apenas supostos - também de estagnação. No intervalo 2007/2010 verificou-se uma substancial redução no crescimento populacional médio municipal para I, $3 \%$ ao ano, uma taxa igual à constatada para o Estado do Rio G. do Norte no seu conjunto (Tabela I). A destinação teria, para alguns, começado a enfrentar sintomas de estagnação com incerta duração. Entretanto, dada a complexidade dos fatores internos e externos que influenciam o desempenho de uma região turística, e também a curva exposta no Gráfico I para a destinação em foco, pode-se mais acreditar é que não há evidências que suportem a hipótese da estagnação para o resort sob estudo. Comportamentos de demanda abaixo das expectativas por alguns anos em um resort não podem, imediatamente, e à revelia dos dados de expansão dos meios de hospedagem, ser necessariamente tomados como marcos iniciadores da estagnação na trajetória do ciclo da destinação.

Acredita-se que a carcinocultura, com menor efeito, foi suplementar ao turismo nos anos de 1990 e começos da década de 2000 na atração de imigrantes para o Município de Tibau do Sul. Estes imigrantes assentaram-se na área municipal próxima aos manguezais, onde alguns pequenos povoados experimentaram forte expansão (margens da Lagoa Guaraíras, afastada cerca I 5 a $10 \mathrm{~km}$ da vila de Pipa). Contudo, o declínio desta atividade foi severo nos últimos anos da década passada, continuando pelos dias atuais, o que ajuda a entender a queda do crescimento populacional no final da década passada. Além disso, pode-se supor que a facilitação da mobilidade na última década permitiu intensificar a pendularidade (mobilidade) para a força de trabalho oriunda dos municípios vizinhos para trabalhar na destinação, como alternativa à residência no - ou migração para - inflacionado município turístico. 


\section{ABORDAGEM GEOGRÁFICA SISTEMÁTICA DA FUNC̣ÃO TURISTICA E O MODELO CICLO DOS RESORTS}

O modelo de ciclo de Butler (I980) é um dos modelos mais influentes em Geografia do Turismo, dentre outros que oferecem tipologias evolutivas ou temporais para as destinações. Seu caráter é ser uma representação teórica sintética da dinâmica regional turística, representação orgânica ou integradora de muitas variáveis tendo como pano de fundo o conceito de Espaço Geográfico. É, em decorrência, modelo classicamente geográfico, no senso que exibe da definição areal e da visão regional de síntese. Levando-se em conta a classificação de Coltman para os ciclos - ciclo curto ou sazonal, ciclo de média duração, e ciclo de longo prazo ou tendência -, o modelo do ciclo dos resorts, ou destinações, ou zonas turísticas, referido encaixa-se na categoria dos modelos cíclicos de tendência ou de longo prazo (COLTMAN, I989, apud GONÇALVES; AGUA, I997, p. I2). A destinação é identificada como a área ou região que é uma porção do Espaço Geográfico definida pelo turismo. O conceito de região - central na Geografia (GOMES, I995; LENCIONI, 2003) - é utilizado para circunscrever territorialmente o assentamento - ou "lugar turístico" na denominação de Cruz (2003, p.I3) - que vai ser submetido à análise tipológico-evolutiva ou temporal.

O modelo encerra a ideia de que o espaço geográfico é regionalizado e se altera - é produzido - por processos, no caso, comandados pelo sistema cultural dos serviços. Algumas análises de destinações inspiradas no modelo procuram mesmo por foco nas alterações acontecidas na base dos recursos naturais ao longo das fases, como Hernandez e Leon (2007) acerca das condições ambientais na fase de pós-estagnação, quando os esforços podem ser dirigidos para a recuperação ambiental da destinação visando o seu rejuvenescimento e que escape do declínio.

A destinação - região turística - tem sua ontologia descrita em etapas ou fases ou estágios sucessivos teóricos. A destinação apresentaria uma sequência de seis fases: I) fase da exploração, 2) fase do envolvimento, 3) fase do desenvolvimento, 4) fase da consolidação, 5) fase da estagnação e, finalmente, a última etapa: 6) a fase do declínio ou a do rejuvenescimento da destinação (Butler, ı980).

Muitos estudiosos já haviam percebido que as destinações iam experimentando mudanças ao longo do tempo. Likorish \& Kershaw (1958, apud CHOY, I992, p.26) descreveram a tendência à substituição dos visitantes ricos pelos visitantes da classe média à proporção que a destinação tornava-se mais antiga; finalmente, a destinação acabava dominada pelos pobres em 
renda, e a região-produto já não era mais aquele "produto" que existira na fase inicial. Observações similares estão nos trabalhos de Christaller (I963, apud BUTLER, I980, p.5), Plog (I973) e Stansfield (I970), entre outros. A ideia básica é que existe uma sucessão diferencial de visitantes (consumidores da destinação) e Butler sistematiza esta ideia inspirando-se no conceito de ocupação sequencial de D. Whittlesey (I929), tal como o observa Johnston (200I, p.5). A metáfora é aspirada dos estudos da ecologia humana, quer dizer, é central a consideração da competição pelo espaço entre as espécies ou suas variedades (no caso, variedades de turistas). A população dos visitantes (os consumidores turísticos) e o meio geográfico (a destinação) são as dimensões sob foco.

Butler argumenta existir um processo acumulativo no espaço (o meio vai mudando) ao longo da evolução de uma área turística. O que vai acontecendo na destinação irá, cumulativa e organicamente, estruturar-se espacialmente e atuar posterior e incessantemente na definição do caráter do lugar, afetando o futuro da destinação. Tal como em toda reunião de objetos materiais e relações sociais, uma destinação possui origem, desenvolvimento e decadência. O modelo de Butler, portanto, se suporta nas ideias ecológicas da dinâmica de populações (WILKINSON, I996, p.I7) associadas à ecologia regional ou da paisagem.

Em torno do modelo rondam muitas críticas, e dentre elas são numerosas aquelas dirigidas à sequência proposta das fases para o desenvolvimento da destinação. O próprio Butler admite que, no caso de o turismo ter se difundido por áreas onde não havia assentamento humano anterior ou em que este assentamento era de pequena importância, não faria sentido considerar os dois primeiros estágios da evolução, isto é, o da exploração e o do envolvimento (BUTLER, I980, p.I I). Nesse particular, foi inspirado justamente nos sistemáticos estudos feitos por Noronha (I976) para o Banco Mundial cuja agência BID financia o Prodetur - que Butler se baseou para evidenciar os limites da sua própria proposta.

Outro crítico das fases argumenta com o exemplo das Ilhas Salomão: aparentavam estar no início do desenvolvimento, mas na realidade já estavam ingressando num "estágio modificado de declínio" (DOUGLAS, I997, p.I7). Ou seja, muitas fases propostas eram irreconhecíveis em certas destinações. E esta "amputação" de fases seria mais comum do que se pensava. Papua Nova Guiné, por exemplo, havia passado dos "primeiros momentos de evolução” para um claro declínio desde I973 (DOUGLAS, I997, p.I7). Para alguns, o comportamento do desenvolvimento das destinações coincidiria com o modelo apenas em poucos casos, e então não se deveria esperar 
muito da sua capacidade preditiva (COOPER, I994, p.344, apud WILKINSON, I996, p.23).

E como identificar a fase na qual estaria a região turística? Agarwal lamentou que o modelo de Butler não oferecesse indicadores claros para que a pesquisa sobre uma determinada destinação pudesse apontar quando a mesma se movia de uma fase a outra. Melhor seria, afirmou, que o modelo atribuísse mais valor aos momentos de superposição (overlapping) entre as fases que se sucedem (AGARWAL, I 997, p.69,70,7I) que às fases propriamente ditas. Tal crítica é de grande utilidade no exame da destinação oferecido pelo presente artigo.

Intervenções funcionais de origem externa ou interna, como a introdução de novas atrações - casas de shows, marinas, instalações esportivas, museus, casas de jogos etc. - podem lançar a destinação em novo(s) ciclo(s) a ponto de alterar toda a lógica de sequências de fase do ciclo anterior. Este é um grande esforço procedido, por exemplo, em velhas destinações, inclusive na Europa Mediterrânea (CHALKITI, 2007, p.I63), para conferir sustentabilidade às destinações de massa. Estas novas atrações poderiam criar uma situação de fases que cortaria os vínculos lógico-sequenciais do quadro atual da destinação com a sua história prévia (CHOY, I992, p.29). O modelo de Butler falharia, nestes casos, em identificar as fases. Poder-se-ia perguntar: estaríamos diante de um novo ciclo com novas fases, ou ainda diante do mesmo antigo ciclo renovado (CHOY, I 992, p.29)?

As controvérsias prosseguem. Uma vez que o foco do modelo é a população de visitantes, já foi perguntado o seguinte: o ciclo da destinação, com as suas fases, seguiria uma única e mesma curva para todos os grupos de turistas oriundos dos diferentes mercados que, ao longo do tempo, se vão sucedendo em uma mesma região turística ou destinação? Moore \& Whitehall, utilizando modelos estatísticos (Markov), concluíram que, no caso de Barbados, o modelo da curva em forma de $S$, de Butler, oferece uma boa imagem para a chegada de turistas no período I957-2002, mas apenas para determinados mercados emissores. Entretanto, não se poderia dizer que o mesmo comportamento da curva representaria os turistas advindos de todos os mercados emissores que chegaram à destinação (MOORE; WHITEHALL, 2005 , p.II2).

Malgrado todas as críticas que possam ser feitas ao modelo do ciclo e sua lógica evolucionária, analistas em geral - inclusive aqueles muito críticos ao modelo - reconhecem seu notável valor e influência, o que se expressa por massivas discussões e reedições de trabalhos (BUTLER, 2006, 2009; TSIAKALI, 2008). 
O modelo do ciclo das destinações ou das regiões turísticas, sendo o mais influente dos modelos evolutivos, compreensivelmente foi submetido a severas apreciações revisionais suportadas em estudos empíricos realizados em diferentes contextos espaciais e temporais. Apesar de todo o volumoso criticismo construído em torno dele, ele é uma referência central nas análises dedicadas ao estudo sistemático da dinâmica das destinações e continua a suscitar ininterrupto, fluente e variado espectro de discussões produtivas sobre a ontologia das regiões turísticas.

No presente artigo, essa ontologia é imaginada e apreciada, especificamente, na sua dimensão ou face demográfica. Uma destinação, claro, apresenta várias dimensões que podem ser estudadas em suas dinâmicas particulares ou específicas. Como explorar melhor uma destas tantas faces da perspectiva ontológica geral do resort? Deve-se reconhecer - inclusive é o que fazem muitos dos mais severos críticos da teoria do ciclo - que a representação sequencial proposta por R. Butler oferece eficiente ferramenta teórica unificadora ou integradora das propriedades da região turística em sua dinâmica. Eis a razão central da utilização do modelo na presente análise das alterações dos padrões demográficos na destinação Tibau do Sul nos últimos vinte anos, posto que o presente artigo empenha-se em integrar a análise das características demográficas da população local (dimensão populacional) à interpretação dinâmica da destinação turística.

\section{A ANÁlISE DEMOGRÁFICA DA POPULAC̣ÃO LOCAL E O TURISMO NA PERSPECTIVA DO DESEN VOLVIMENTO DA DESTINAC̣ÃO OU REGIÃO TURÍSTICA}

Não restam dúvidas que a preocupação em torno das relações entre o turismo - como uma função de amplos efeitos territoriais - e os estudos de população é atitude já assentada nos ambientes acadêmicos e de consultoria interessados nas atividades e nos lugares de lazer, visitas e entretenimento. Vários modelos desenvolvidos durante as últimas décadas inspiraram-se nas alterações que a distribuição geográfica da população local experimentava em decorrência do desenvolvimento ou da expansão da função turística.

Mesmo formulações ou modelos voltados para explorar as dimensões de Origem/Destino, como o de Lundgren ( I982) - que classifica os destinos como metropolitanos, periféricos urbanos, periféricos rurais e de ambiente natural -, ou a representação de Turner \& Ash (I976) (centro ou metrópoles/periferias), trazem em si ou denotam na sua linguagem atenção às 
concentrações ou distribuições das populações. O próprio índice de Defert ( 1967 ) avaliando a importância da função turística numa região resulta da relação entre o número dos leitos disponíveis numa determinada região turística $(N)$ e a sua população local $(P)$.

Não obstante a tudo isso, os estudos de segmentação demográfica (perfis demográficos) dos visitantes, isto é, dos consumidores ou turistas, são eles compreensivelmente muito mais numerosos na bibliografia que procura incorporar a análise demográfica à turística, uma vez que tais estudos são vitais para os interesses de curto e médio prazo da denominada indústria do turismo. É mesmo consagrada a expressão estratégia de segmentação (JUANEDA; SASTRE, I999), para alcançar população determinada - certo perfil - dos consumidores. Esses estudos demográficos formam uma importante parte auxiliar aos denominados estudos dos fluxos turísticos ou da demanda.

Observe-se que os modelos evolucionários, tais como o de Butler (I980), ou o de Thurot (1973), ou de Plog (I973), são baseados na sucessão desta população (consumidores), isto é, da população dos visitantes (turistas) segundo os seus estilos de consumo ou segundo as suas classes de renda (segmentação em perfis), ou ambos os critérios combinadamente. Propõem eles que, ao longo do tempo, tem lugar na destinação uma sequência reconhecível de segmentos (tipos de perfis) demográficos diferentes de visitantes. A população dos visitantes é representada como mudando à proporção que o tempo passa, mudando em seus quantitativos segundo os estilos de vida e de consumo, segundo os grupos de idade, segundo os níveis de renda, isto é, o caráter do fluxo se vai alterando à proporção que a destinação ou região turística vai desenvolvendo. Os padrões demográficos dos visitantes sofrem mudanças.

Quando as atenções institucionais de pesquisa das grandes iniciativas de investimentos e vendas do serviço turístico - crescentemente operando à escala global - se voltam para as secções do Espaço Geográfico que são ou podem se tornar destinações (zonas receptivas), o foco é posto, naturalmente, de modo exclusivo nas características naturais ou culturais da área que podem cooperar para formatar os produtos turísticos, ou que podem ser disfuncionais às estratégias espaciais de expansão. Então, certa preocupação com a disponibilidade e características da mão de obra local a ser incorporada ao mercado de trabalho do setor se constitui exceção à reconhecida desatenção à demografia da população local. Pode-se pensar que, de certa forma, isto é reflexo do tradicional planejamento de cima para baixo rotineiramente associado à história de implementação dos muitos planos estratégico-espaciais para o setor, o que tem dado espaço a justificados criticismos 
(ARAÚJO, 20I 2; ARAUJO, BRAMWELL, 2002; ARAUJO, DREDGE, 20I 2; LIU, WALL, 2006).

Os modelos de segmentação evolucionária, antes referidos, não analisam a população local sistemática ou diretamente numa perspectiva de fases ou evolucionária. Entretanto, a população dos habitantes da destinação compartilha do processo das mudanças precipitado pela ontologia da destinação turística, desenvolvimento este que conduz em geral à estandardização ou institucionalização turística da região receptora.

Em decorrência de tudo isso, entendemos como necessária a avaliação daquilo que acontece à população local: como é a sua ontologia, como ela muda em seus caracteres demográficos (etariamente, educacionalmente, migratoriamente etc.) à medida que a destinação descreve a sua trajetória de alterações.

Quanto à distribuição no espaço da população local nas regiões turísticas (destinações), outros modelos contemplam muito própria e precisamente o assunto. O proposto por Miossec ( I976) pressupõe cinco etapas-padrão da organização espacial numa região turística. Neste caso, enquanto a primeira etapa mostra, entre outras características, baixas densidades demográficas e isolamento entre os assentamentos humanos, a última etapa é, pelo contrário, caracterizada pelas altas densidades demográficas e pela hiperconectividade entre os assentamentos turísticos. Lozato-Giotart (I993, p.I25) observa, por seu turno, baseando-se em J. Lundgren, o modo como o processo de crescimento populacional metropolitano vai absorvendo ou colonizando a zona de segunda residência para a população residente metropolitana; o crescimento populacional da metrópole prossegue requalificando sequencialmente novas e mais distantes áreas rurais para a função de zona das residências secundárias.

Entretanto, apesar desse interesse no aspecto da distribuição espacial da população, o Grupo de Estudos em Turismo da União Geográfica Internacional (UGI), há cerca de uma década, entendeu de estabelecer como foco claro e relevante de pesquisas os nexos entre o turismo e os estudos mais amplos da população; especificamente, as relações entre o turismo e o fenômeno das migrações.

Havia o reconhecimento, entre os estudiosos do turismo numa perspectiva geográfica, que chegara o tempo de desenvolver estudos sobre aspectos ainda pouco analisados (Hall, Williams, 2002, p.3) ou a merecer reexame à luz das novas realidades do espaço turístico. Existiam evidências que estudos de ordem demográfica, claramente interconectados com as destinações, eram escassos, como o demonstraram Botterill, Haven e Galé (2002). Os 
primeiros resultados de tais investigações apareceram no número temático Turismo e Migrações, do periódico Tourism Geographies (2000, vol.2, n.2, February), inspirado, principalmente, na experiência dos espaços turísticos do mundo desenvolvido.

Deste empenho resultou que palavras indicadoras de classes de mobilidade - pendularidades diversas, migração de trabalho, de retorno, de aposentados, empresarial etc. -, que não raro se superpõem, tornaram-se menos escassas na bibliografia da Geografia do Turismo, deste modo incorporando-se mais frequentemente à análise do turismo os temas da mobilidade, migração e circularidade, central na Geografia contemporânea. Das mencionadas discussões decorreu a ideia norteadora de que o turismo pode ser entendido como envolvendo duas grandes formas de mobilidade. Uma é aquela denominada de mobilidade do trabalho ou da produção, entendida como orientada para resolver o provimento dos serviços turísticos, forma importante especialmente onde o turismo é de massas e de expansão rápida e que necessita mão de obra adicional, isto é, além da capacidade da oferta local. A outra, denominada mobilidade de consumo, é devida aos deslocamentos produzidos pelos próprios consumidores ou turistas (WILLIAMS, HALL, 2000, p.II).

Voltado propriamente para o estudo da mobilidade do trabalho, então no âmbito daquela iniciativa da UGI, mencione-se o trabalho de Szivas \& Riley, artigo que aborda (revisa) o tema da entrada da mão de obra advinda do desemprego ou de outros setores (agricultura, por exemplo), na atividade turística (movimento intersetorial do trabalho). Como era de esperar, movimento que se associa fortemente à mobilidade geográfica.

Esses autores reapresentam algumas discussões e argumentos desenvolvidos em torno da mobilidade nas experiências do turismo periférico nas áreas rurais ao longo das décadas precedentes (2002, p.54-5), replicando-os em artigo posterior (SZIVAS, RILEY, AIREY, 2003). Atenção especial merece o trabalho produzido por Salva-Tomàs estudando características demográficas dos imigrantes recentes na área turística segundo a origem geográfica dos mesmos, e a segmentação existente no mercado de trabalho turístico fortemente entrelaçado com estas origens. De maneira mais ampla, o autor procura relacionar as migrações (quanto à origem), no caso tanto a de trabalho quanto a de consumo, à expansão do turismo de massa nas Ilhas Baleares, Espanha, a partir dos anos de I950, identificando as mudanças. As alterações verificadas no perfil demográfico dos residentes são identificadas, inclusive etariamente, que é o caso do rejuvenescimento da população (SALVA-TOMÀS, I996, 2002). 
Para a discussão destes problemas, da associação entre a mobilidade intersetorial e geográfica, pode-se retomar a observação de Singer (I980) de que, não obstante existam zonas de expulsão, são as zonas de atração onde se encontram as demandas por força de trabalho que acabam por definir as trajetórias da mobilidade geográfica (SINGER, I980, p.226). A generalização pelo território nacional das políticas de transferência de renda e cobertura social implantadas a partir do final dos anos de I990, e intensificada na última década acreditamos não alteraram este fenômeno gravitacional comandado pelas zonas de desenvolvimento diferenciado, que é precisamente o caso turístico de Tibau do Sul. Para a produção do serviço turístico, um determinado estoque de força de trabalho há que ser reunido num sítio geográfico onde o serviço vai ser consumido (WILLIAMS, HALL, 2000, p.I3), e isso comanda a direção da mobilidade geográfica no rumo de uma região.

Abriu-se um campo de possibilidades para os estudos sobre os padrões reais de mobilidade do trabalho, isto é, sobre diversificados tipos de circulação ou de migração vinculada à produção (BELL; WARD, 2000). Os estudos vão suscitando indagações e reflexões; nesse aspecto cumpre observar as anotações desenvolvidas por Brito acerca do descolamento entre as condições da mobilidade espacial e as condições da mobilidade social nas décadas mais recentes no Brasil (2009, p.2I). Esse problema é particularmente importante no campo da análise das potencialidades migratórias para as zonas de forte desenvolvimento dos serviços turísticos. É que a globalização, as específicas exigências de interação e inserção nas redes sociais como requerimentos de trabalho, a internacionalização das destinações, isto e muito mais, têm evidenciado a importância da migração internacional no setor (AITKEN, HALL, 2000), sobrepondo-se à força da proximidade, à diferença do que pode ocorrer a outros setores. O problema exige a análise do caráter ou perfil da mobilidade geográfica ao nível das diferentes escalas geográficas. De certa forma, pode-se dizer que isso se associa ao que Brito denomina de restrições crescentes da inserção da força de trabalho por conta da reestruturação no país (BRITO, 2009, p.I9; OJIMA, 20I 2, p.I 5 I).

Com a generalização da mobilidade, fato já anunciado por Zelinky (I97I), e com a superação em muitos espaços geográficos, como no Brasil, da dominância do clássico padrão de migração campo (agricultura) $\rightarrow$ cidade (indústria), atenções têm sido postas nas migrações de retorno, não restritamente ao retorno dos agora aposentados que haviam formado os fluxos do padrão clássico das áreas rurais para as metrópoles (fluxos nacionais ou internacionais), mas também dos migrantes de retorno de diferentes faixas etárias e perfis socioprofissionais. Exemplo é o estudo sobre migrações de retorno em 
velhas áreas de plantations (CONWAY, POTTER, 2007) na América, áreas envolvidas há décadas por esquemas de desenvolvimento turístico de massas. Há exemplos de estudos voltados para a avaliação da migração de áreas urbanas (metrópoles) para áreas periféricas, áreas mais naturais ou rurais, em função da instalação da atividade turística nestas zonas e oportunidades profissionais e de investimentos então decorrentes (PANIÁGUA, 2002), constituindo-se numa variedade do que se tem chamado de contraurbanização.

É evidente que a destinação turística, inclusive a sob exame no presente trabalho, não é apenas afetada nas suas características demográficas pela ação dos investidores turísticos e das políticas públicas diretamente vinculadas ao setor. As circunstâncias regionais da agricultura exercem suas influências, assim como políticas públicas de efeitos com extensão geral ao território do país, tais como transferências de renda (aposentadorias e benefícios da previdência, programas de complementação de renda, habitacionais etc.), extensão de redes de saúde e educação etc. Campos, Barbieri e Carvalho (2007) estudaram as relações entre migração e previdência social no Brasil entre I980 e 2000; trata-se de um fenômeno extenso e significativo para a interpretação da mobilidade no país (GUEDES, 2005). De fato, como o observa Massey (2005, p.I48) em geral, o espaço - e no caso uma região turística como a em foco - é uma esfera de relações e de multiplicidades contemporâneas, que, no caso, inclui tanto a dimensão mais propriamente dos fatores turísticos quanto os demais, como políticas sociais, reestruturações produtivas etc.

Existem processos em generalizada difusão, como o envelhecimento da população, o declínio da mortalidade e da fecundidade, fenômenos associados à difusão dos padrões da transição demográfica (vital) no Brasil já numa segunda fase. Ou o aumento da mobilidade territorial ou geográfica no país à proporção que a modernização se espalhou pelo espaço geográfico alterando seus sistemas de transporte e comunicação (transição de mobilidade), isto associado às restrições de inserção crescentes no mercado de trabalho, restrições antes mencionadas (BRITO, 2009). Ou a transição ocupacional, como o espalhamento das atividades de serviços (educação, saúde, energia, comunicações etc.) pelo espaço como aspecto do que se chamou revolução pós-industrial (DANIELS, I993; STANBACK et al, I983), o que alterou os padrões gravitacionais para os fluxos. Entretanto, há na literatura naturais evidências que zonas forte e diferencialmente afetadas por uma atividade

2 Silva (2005) e Pagnato \& Becker (2007), por exemplo, examinam a influência da atividade petrolífera na região de Macaé. 
como o turismo tendem a apresentar também características demográficas diferenciadas (SZIVAS, RILEY, AIREY, 2003; SALVA-TOMÁS, I 996, 2002).

\section{O DESENVOLVIMENTO DE PIPA E AS ALTERAC̣ÕES NOS PADRÕES DEMOGRÁFICOS}

Esclarecemos, a princípio, que a unidade de observação estatística é o Município. Para que fossem avaliadas as alterações demográficas experimentadas pelo Município de Tibau do Sul (a destinação turística) ao longo do seu desenvolvimento nas décadas 1990 e 2000 , tomou-se para efeito de comparação ou contraste o Município de Espírito Santo, localizado no Agreste do Estado e a cerca de $40 \mathrm{~km}$ de T. do Sul, como já informado. E. Santo, o município contraste, não sofreu nenhum processo local que pudesse ser identificado como de dinâmica estrutural, nenhum processo diferenciador local (seja de serviços turísticos, petróleo/gás, fruticultura, dinâmica metropolitana periférica, serviços de logística, ou outro). Então, se assume possa ele expressar a trajetória, digamos, normal, dos padrões demográficos no contexto regional nas décadas de I 990 e 2000, trajetória da qual o Município de Tibau do Sul se desviou por conta de ter se tornado uma destinação turística de sucesso.

Eis, em resumo, o material que será analisado: ı.Taxas geométricas médias anuais de crescimento da população; 2.Indicadores dos padrões da população segundo idade, sexo e escolaridade nos anos de I99I, I996, 2000, 2007, 2010; 3.Exploração dos dados migratórios dos anos censitários 2000 e 20 Io no sentido de identificar mudanças nos padrões de migração ao longo do desenvolvimento da região/destinação turística, e avaliar de que forma as migrações influenciaram nos perfis ou padrões demográficos.

As alterações nas características demográficas são interpretadas flexivelmente à luz do processo de expansão da função turística, e tal processo de desenvolvimento é expresso pelo Gráfico I que figura o crescimento dos meios de hospedagem.

\section{As alterações na Dinâmica do Crescimento da População Local}

As alterações verificadas, ao longo de quatro décadas, na relação entre as populações residentes nos dois Municípios, Tibau do Sul e Espírito Santo 
estão na Tabela 2. Notável que as duas unidades territoriais acabaram, afinal e na década passada, por permutar a posição de ostentar a maior população, isso em função da dinâmica turística que vem tendo lugar em Tibau do Sul nas duas últimas décadas. Em I970, a população de T. do Sul (3.897 habitantes) era cerca de $2 / 3$ da população residente no Município de Espírito Santo (6.I43 habitantes) naquele ano; porém, a partir dos meados da década de 2000, passa a ser maior (Tibau: II.385 hab.; E. Santo: I0.475).

Tabela 2 - Relação da População Residente em T.do Sul e E. Santo. 1991 a 2010. RN

\begin{tabular}{llllllll}
\hline ANOS & 1970 & 1980 & 1991 & 1996 & 2000 & 2007 & 2010 \\
\hline Relação* $0^{*}$ Sul/ESa & 0,63 & 0,66 & 0,59 & 0,65 & 0,72 & 1,08 & 1,09 \\
\hline
\end{tabular}

Fontes: IBGE. Contagem de população. $(1996,2007)$. Rio de Janeiro.

IBGE. Censos demográficos (1970, 80, 91, 2000, 2010). R. de Janeiro.

*Obs. 1: Relação definida pela seguinte Fórmula:

Pop. Residente no M. de Tibau do Sul $\div$ População residente no M. de Espírito Santo.

A Tabela 3 compara as taxas de crescimento populacional ostentadas pelas duas unidades municipais nos últimos trinta anos. Nota-se que na década de I980 a taxa de crescimento populacional média geométrica anual (em \%) no Município de E. Santo era sensivelmente superior àquela verificada para Tibau do Sul. Pode-se sugerir, aceitando-se a premissa realista de que os padrões de fecundidade deveriam ser equivalentes, maiores perdas por emigração para este último município (Tibau do Sul). A situação passa a se alterar na década seguinte, década de I990, com as perdas se acentuando para E. Santo e reduzindo-se acentuadamente para Tibau do Sul. Pode-se afirmar, apoiando-se ainda na Tabela I - que indica a taxa média anual de 6,80\% para Tibau no período de I996/2000 - que os anos da mais intensa imigração para o resort foram os dez anos entre meados dos anos de 1990 e meados da década seguinte. Este é justamente o segmento da linha do tempo da destinação mais convincente para que chamemos de core da fase do desenvolvimento.

Observa-se um crescimento sustentado da taxa de crescimento populacional para o Município de Tibau desde a década de I980 até à Contagem de População de 2007. Sendo a última taxa calculada para o decênio, isto é, de 2000 a 20 Io, vê-se o movimento como ainda ascendente, década a década, desde I980. Os dados da última Contagem de População (2007), entretanto, produzem uma visão mais realista do que realmente passou a acontecer no 
resort nos anos finais da década de 2000 (entre 2007 e 2010 ), em termos do seu crescimento populacional. Tem lugar uma vertiginosa queda na sua dinâmica populacional, com a taxa praticamente se equalizando à verificada para Espírito Santo no mesmo triênio, e sendo menor que a do Rio G. do Norte em seu conjunto. E foi mesmo inferior ao seu próprio crescimento médio anual para os anos de i 980.

Tabela 3 - Taxa do crescimento geométrico médio anual (\%) da população residente nos intervalos entre os Censos e Contagens nos Municípios indicados, 1980-2010

\begin{tabular}{llllll}
\hline MUNICÍPIOS & $1980 / 1991$ & $1991 / 2000$ & $2000 / 2007$ & $2007 / 2010$ & $2000 / 2010$ \\
\hline E. SANTO & 2,85 & 0,64 & $-0,80$ & 1,12 & $-0,23$ \\
\hline TIBAU DO SUL & 1,85 & 2,95 & 5,08 & 1,28 & 3,92 \\
\hline ESTADO DO RN & 2,21 & 1,56 & 1,17 & 1,68 & 1,32 \\
\hline
\end{tabular}

Fontes: IBGE. Censos demográficos (1980, 1991, 2000, 2010). R.J. IBGE. Contagem (2007). Rio de Janeiro.

\section{AS ALTERAC̣ões NO PERFIL POR SEXO dA POPULAC̣ÃO LOCAL}

O que se pode concluir da Tabela 4, que expõe a Razão de Sexo nas duas unidades municipais que estão sendo comparadas, é que não são registradas diferenças significativas entre os padrões verificados para os dois Municípios em cada um dos anos com dados disponíveis. A transformação do Município de Tibau do Sul numa destinação turística de sucesso não acarretou alterações na sua Razão de Sexo. Entretanto, deve-se notar que no ano de 1996 (ano de Contagem) a Razão de Sexo foi ligeiramente superior para o Município de Tibau do Sul. Esse fato talvez esteja associado à fase bem intensa da construção de hotéis e pousadas (entrada de mão de obra masculina), inclusive hotéis do tipo resorts, quando a destinação estava justamente na fase do take off. Observa-se ainda que, em I99I, a Razão de Sexo era sensivelmente maior em Espírito Santo, e por hipótese, podemos pensar que tal diferencial resulta da natureza diferente da absorção de mão de obra segundo sexo das atividades primárias existentes em cada um dos municípios à época. Enquanto em E. Santo dominava a pecuária e a agricultura de roças (milho, feijão etc.), em Tibau do Sul, ao lado da agricultura de roças, havia a forte presença da atividade extrativista ("marisqueira" nos manguezais), ao lado da pesqueira e da carcinocultura. 
Tabela 4 - Razão de Sexo* da população residente nos Municípios indicados para os anos de 1991, 1996, 2000 e 2010

\begin{tabular}{lllll}
\hline ANO & 1991 & 1996 & 2000 & 2010 \\
\hline E. SANTO & 121,18 & 104,91 & 105,43 & 103,16 \\
\hline TIBAU DO SUL & 104,25 & 110,03 & 104,46 & 102,33 \\
\hline ESTADO DO RN & 95,30 & 95,45 & 95,99 & 95,66 \\
\hline
\end{tabular}

Fontes: IBGE. Censos (1991, 2000, 2010). R.J. IBGE. Contagem (1996). Rio de Janeiro.

${ }^{\star}$ Razão de Sexo $=H / M \times 100$

\section{ALTERAC̣õES NO PERFIL ETÁRIO dA POPULAC̣ÃO LOCAL}

$\mathrm{Na}$ Tabela 5 acham-se expostas as seguintes taxas, nos dois Municípios indicados, para os anos de I99I, I996, 2000 e 2010: a Taxa de Dependência Geral (TDG), a Taxa de Dependência Infantil (TDInf) e a Taxa de Dependência dos Idosos (TDId). É clara a evidência que a Taxa de Dependência Geral (TDG) declina, de I99I a 20I0, mais acentuadamente no caso do Município de Tibau do Sul que no caso do Município de Espírito Santo. No ano de I99I, a TDG registrada para Tibau do Sul $(97,8$ I) era maior que a taxa para o Município de Espírito Santo (95,3 I). Ao longo do período de vinte anos, ambas as taxas se reduzem significativamente em relação ao padrão de I99i. É ao longo dos anos de I990, a década do começo da difusão do turismo, que a TDG para Tibau do Sul ostenta mais acelerada queda. Resultado deste processo é que, ao se olhar as taxas para o ano de 20 Io, a mesma (TDG) é significativamente menor em Tibau do Sul que a registrada para Espírito Santo. A população de Tibau do Sul exibe um padrão etário mais centrado na faixa que compreende as pessoas entre os I 4 a 65 anos de idade.

Tabela 5 - Taxa de Dependência Geral, Infantil e de Idosos` nos Municípios indicados nos anos de 1991, 1996, 2000 e 2010

\begin{tabular}{lllll}
\hline \multirow{2}{*}{ MUNICÍPIOS } & \multicolumn{5}{c}{ ANOS } \\
\cline { 2 - 5 } & 1991 & 1996 & 2000 & 2010 \\
& DG. TDINF. TDID & TDG. TDINF. TDID & TDG. TDINF. TDID & TDG. TDINF. TDID \\
\hline E. SANTO & 95,$31 ; 82,19 ; 13,12$ & 84,$16 ; 70,43 ; 13,73$ & 79,$33 ; 65,54 ; 13,79$ & 59,$53 ; 46,10 ; 13,75$ \\
\hline TIBAU DO SUL & 97,$81 ; 84,35 ; 13,47$ & 60,$61 ; 53,32 ; 8,29$ & 68,$68 ; 57,01 ; 11,67$ & 51,$59 ; 42,84 ; 8,75$ \\
\hline ESTADO DO RN & 76,$21 ; 65,77 ; 10,44$ & 67,$82 ; 57,31 ; 10,51$ & 61,$27 ; 50,98 ; 10,29$ & 47,$86 ; 46,65 ; 11,20$ \\
\hline
\end{tabular}

Fontes: IBGE. Censos (1991, 2000, 2010). R. J; IBGE. Contagem (1996). Rio de Janeiro.

*- (TDG) Taxa de Dependência Geral $=100$ x (Pop. 0-14 anos + Pop. 65 anos ou mais) $\div$ P de 15-64 anos.

- (TDIn) Taxa de Dependência Infantil = $100 \times$ Pop. 0-14 anos $\div$ Pop. 15-64.

- (TDId) Taxa de Dependência de Idosos = 100 x Pop. 65 anos ou mais $\div$ Pop 15 a 64 anos. (Plane, Rogerson, 1994). 
Os dados exibidos na Tabela 5 mostram que a Taxa de Dependência de Idosos (TDId) para o Município de Espírito Santo mantém-se praticamente inalterada durante as duas décadas (em I99I foi de I3, I2, e em 20 Io foi de I 3,75 ), enquanto a mesma taxa para o Município de Tibau do Sul - que em I99I foi de $\mathrm{I} 3,47$, valor próximo ao da taxa para E. Santo - declina severamente. Isto sustenta a afirmação antes feita acerca dos diferentes perfis etários das duas regiões (municípios) sob processo de comparação. E, ainda seguindo o mesmo raciocínio, como a população residente no Município de Tibau é muito centrada na faixa de reprodução, é compreensível que a Taxa de Dependência Infantil para o Município de Espírito Santo não seja tão mais alta que a mesma taxa registrada para o Município de Tibau do Sul. Mas o fato é que a Taxa de Dependência Infantil (TDInf), que era ligeiramente maior em Tibau do Sul quando comparada com a taxa para E. Santo em I99I veio a ser menor para o ano de 20 Io.

A Tabela 6, ainda que contenha informações redundantes em relação à Tabela 5, oferece medidas mais diretas para avaliar a presença dos jovens ou dos idosos nas populações residentes nos dois municípios que estão sendo comparados quanto aos padrões descritivos ou perfis demográficos que exibem. Espírito Santo, não afetado por dinâmica de alteração funcional, continuou mantendo a sua Taxa de Idosos (população residente com 60 anos ou mais de idade) mais alta que a de Tibau do Sul, e mesmo aumentou a taxa de I 99 I $(9$, I 4$)$ a 20 Io (I 2,0I). No caso do município que é destinação turística (Tibau do Sul), a taxa, que em r99 I era próxima à de E. Santo (9,07), declina para 8,46 em 2010 .

Por outro lado, ainda na Tabela 6, constata-se que a Taxa de Adultos Jovens (TAJ) (aqueles residentes com idades entre I 8 a 39 anos), taxa que era praticamente igual em ambos os municípios no ano de I99I, passa, a partir de I996, e até 20I0, a ser sustentadamente mais alta em Tibau do Sul. 
Tabela 6 - Taxa de Idosos (TId)* e Taxa de Adultos Jovens (TAJ) ${ }^{\star \star}$ da população residente nos Municípios indicados nos anos de $1991,1996,2000$ e 2010

\begin{tabular}{lllll}
\hline \multirow{2}{*}{ MUNICÍPIOS } & \multicolumn{5}{c}{ ANOS } \\
\cline { 2 - 5 } & 1991 & 1996 & 2000 & 2010 \\
& TID / TAJ & TID / TAJ*** & TID / TAJ & TID / TAJ \\
\hline E. SANTO & $9,14 / 29,01$ & $9,90 / 26,18$ & $10,23 / 31,91$ & $12,01 / 34,43$ \\
\hline TIBAU DO SUL & $9,07 / 28,74$ & $7,00 / 29,47$ & $9,14 / 35,70$ & $8,46 / 39,21$ \\
\hline ESTADO DO RN & $8,24 / 33,54$ & $8,53 / 30,76$ & $9,03 / 36,14$ & $10,84 / 37,47$ \\
\hline
\end{tabular}

Fontes: IBGE. Censos Demográficos (1991, 2000, 2010). Rio de Janeiro.

IBGE. Contagem de População (1996). Rio de Janeiro.

${ }^{*} \mathrm{Tld}=$ Pop. 60 anos ou mais / Pop. Total $x 100$.

${ }^{* \star}$ TAJ = Pop. de 18 a 39 anos / Pop. Total $x$ 100. (Anos de 1991, 2000 e 2010).

$* \star \star 0$ Observamos que a TAJ para 0 ano de 1996 é calculada com o limite inferior do intervalo diferente da calculada para os anos de 1991, 2000 e 2010, em decorrência da forma de publicação dos dados. Nela, 0 intervalo das idades é: de 20 a 39 anos (inclusive), e não de 18 a 39 anos (inclusive) como na obs. ${ }^{* \star}$.

\section{ALTERAÇÕES NO PERFIL EDUCACIONAL DA POPULAC̣ÃO LOCAL}

A variável que descreve o(s) nível (eis) da instrução formal da população residente com ro ou mais anos de idade revela-se particularmente comunicativa na identificação da diferenciação que passa a acontecer nos padrões ou perfis demográficos entre os dois municípios (Tabela 7). A participação populacional relativa (\%) na faixa de menor instrução é acentuadamente mais alta no Município de Espírito Santo, no ano de 2oro, que no Município de Tibau do Sul.

Tabela 7 - Pessoas de 10 anos ou mais de idade, por nível de instruc̦ão (\%), nos Municípios indicados, para 0 ano de 2010

\begin{tabular}{|lcc|}
\hline NÍVEL DE INSTRUÇ̃̃O & ESPÍRITO SANTO (\%) & TIBAU DO SUL (\%) \\
\hline A.SEM INSTRUÇ̃̃O E FUNDAMENTAL INCOMPLETO. & 75,4 & 63,5 \\
\hline B.FUNDAMENTAL COMPLETO E MÉDIO INCOMPLETO. & 12,4 & 14,5 \\
\hline C.MÉDIO COMPLETO E SUPERIOR INCOMPLETO. & 10,7 & 17 \\
\hline D.SUPERIOR COMPLETO. & 1,5 & 5 \\
\hline TOTAL & 100 & 100 \\
\hline
\end{tabular}

Fonte: IBGE. Censo demográfico (2010). Rio de Janeiro. 
Quando, contudo, são consideradas as faixas de instrução C e D - que somadas incluem a população dos escolarizados com curso de nível médio completo ou mais (inclusive curso superior seja completo ou incompleto) -, a importância dessas duas faixas somadas, para o Município de Tibau do Sul é efetivamente mais que o dobro do verificado para o Município de Espírito Santo. Certamente se verifica o fenômeno da importação dos padrões educacionais por conta dos requerimentos ou exigências do mercado de trabalho, fato muito reconhecido nas áreas que recebem forte influxo de imigrantes e relembra o postulado teórico da natureza seletiva do fenômeno das migrações apresentado na revisão bibliográfica. É possível então concluir que os padrões diferenciais de educação que se evidenciam pela Tabela 7 resultam do processo de entrada e acumulação migratória, ao longo de duas décadas, na destinação turística Tibau do Sul.

\section{OS PADRÕES MIGRATÓRIOS E A DIFUSÃO TURÍSTICA}

A Tabela 8 identifica, em termos relativos (taxa em \%), os brasileiros natos residentes em cada um dos dois municípios que são identificadas como Migrantes. Estes, os Migrantes, podem ser considerados Migrantes em geral, ou serem considerados Migrantes de Retorno, devendo-se observar que estes últimos acham-se incluídos na categoria dos Migrantes em geral.

Examinando os dados para o ano de 2000 , pode-se constatar que a Taxa Geral de Migrantes é bem aproximada para os dois municípios, sendo mesmo ligeiramente menor para Tibau do Sul, registro que não deixa de ser intrigante e contrário à expectativa teórica. Para o ano de $20 \mathrm{IO}$, entretanto - e certamente decorrência dos efeitos do turismo -, o indubitável influxo maior de imigrantes em Tibau do Sul acabou por se expressar no levantamento censitário, de maneira que a Taxa Geral de Migrantes tornou-se sensivelmente maior para Tibau do Sul, o município resort, quando comparada com a Taxa para o Município de E. Santo (Tabela 8). Mas, observe-se ainda que a Taxa Geral de Migrantes é substancialmente aumentada para ambos os municípios, e a Taxa dos Migrantes de Retorno aumenta também para os dois municípios, quando se compara os dados registrados para o ano de 2000 e para o de 20 io. 
Tabela 8 - Taxas da População (residente) Migrante nos Municípios de Espírito Santo e Tibau do Sul segundo duas categorias (em \%), em relação ao total dos residentes, para os anos 2000 e 2010

\begin{tabular}{|llllll|}
\hline CATEGORIAS DE MIGRANTES & \multicolumn{3}{c}{ M. DE ESPÍRITO SANTO } & \multicolumn{2}{c|}{ M. DE TIBAU DO SUL } \\
\hline & ANO DE 2000 & ANO DE 2010 & ANO DE 2000 & ANO DE 2010 \\
\hline MIGRANTE* & 19,3 & 34,7 & 17,2 & 44,3 \\
\hline MIGRANTE DE RETORNO* & 2,4 & 4,7 & 1,7 & 3,8 \\
\hline
\end{tabular}

Fonte: IBGE. Censos demográficos 2000 e 2010. Rio de Janeiro.

Nota: *A categoria Migrante no município Y é o residente no município $Y$ que não nasceu neste município $Y$, mais os residentes que, mesmo tendo nascido em $Y$, moraram em outro município em alguma (s) fase(s) das suas vidas, isto é, são ou formam a categoria Migrantes de Retorno (exibem experiência migratória). 0 que se entende então como Migrante (municipal) envolve, para usar uma linguagem comum, os 'forasteiros' e mais os 'filhos-da-terra' retornados. 0 que se denomina Migrante, nesta Tabela 8 e na Tabela 9 é, portanto, este somatório (Migrante municipal)

Os dados antes apresentados sugerem que se pergunte acerca das épocas de chegada dos fluxos migratórios, e a Tabela 9, a seguir, expõe o Tempo de Residência (moradia) dos Migrantes segundo as categorias da migração. Os dados do Censo de 2000 permitem olhar a formação do estoque migratório, por tipo de migrante, do ano de 2000 para trás segundo intervalos temporais. Vejamos primeiramente o caso dos Migrantes em geral (ou total T); em seguida, dos migrantes que não são filhos da terra (os chamados Migrantes "Forasteiros", MF); e, por último, o caso dos migrantes de retorno (Migrantes de Retorno, MRet), isto é, aqueles que são os filhos da terra que retornaram, comparando os seus fluxos em cada município, segundo a época que eles retornaram ao município de nascimento.

Sobre os Migrantes em geral (T), divisa-se, com nitidez, que o período de chegada, do estoque migratório total que já estava residindo no Município de Tibau do Sul no ano 2000, foi marcadamente o período de 1997 a 2000, fase de intensa aceleração na expansão deste resort turístico. Os migrantes, declarados em 2000, com menos de dez anos de residência, isto é, os chegados durante a década de I990, a da expansão turística em Tibau do Sul, eram também mais representativos no Município turístico que no Município de Espírito Santo. Mais precisamente, enquanto os migrantes entrados em Tibau do Sul na década de I 990 representavam cerca de 60, I $4 \%$ do estoque dos migrantes no ano de 2000 , os entrados no mesmo período no Município de Espírito Santo representavam 49,6I\%. 
Ainda acerca dos Migrantes em geral (T), e desta vez observando os estoques registrados em ambos os municípios no ano de $2010-0$ padrão dez anos depois do ano 2000, antes exposto -, a força das migrações mais recentes, entendendo-se como mais recentes as acontecidas entre $200 \mathrm{I}$ e $20 \mathrm{IO}$, para o total de migrantes continua a evidenciar-se mais forte para Tibau do Sul, inclusive para todas as faixas de Tempo de Residência definidas, quando em comparação com o Município de Espírito Santo. A Migração geral da década de 2000, em Tibau do Sul, representou 58,52\%, e em E. Santo $42,52 \%$. Nas duas décadas, portanto, o município resort recebeu fluxos mais renovados de migrantes.

Quanto aos Migrantes "forasteiros" (MF), a chegada deles é muito concentrada nos anos finais da década de 1990 em Tibau do Sul; e não se revela diferenciação temporal significativa de chegadas no caso de E. Santo. Também no município que é destinação turística (Tibau do Sul) os migrantes deste tipo ("forasteiros") chegados na década são bem mais representativos que os chegado a mais de ro anos, quando se os compara com a situação no Município de Espírito Santo. Os dados registrados no ano de 20Io, também para o estoque, mostram que a importância relativa dos "forasteiros" é sempre maior, ao longo de todas as faixas de tempo da década de 2000 , para Tibau, e também que a superioridade relativa dos forasteiros deixa de ser tão pronunciada nos anos finais desta década quando comparada com a década de I 990 neste mesmo município.

Os Migrantes de Retorno, nos últimos anos da década de I990, tornam-se bem menos significativos no conjunto dos migrantes, no Município de Tibau do Sul, em função da maior chegada dos "forasteiros" (MF). Dez anos depois, olhando-se os dados registrados para 2010 , observa-se que no final da década de 2000 os Migrantes de Retorno (MRet) retomam alguma importância em relação aos "forasteiros" (MF), e estes anos correspondem justamente ao período da forte queda na dinâmica do crescimento populacional em Tibau do Sul, quando a taxa geométrica média de crescimento anual da população neste município passou de 5,08 no período $2000 / 2007$, para I, $28 \%$ no período $2007 / 2010$. 
Tabela 9 - Total de Migrantes (T), Migrantes Não-nascidos no Município (MF) e Migrantes de Retorno (MRet), nos Municípios indicados, segundo o Tempo de Residência, em anos, no município, com importância relativa (em \%), nos anos de 2000 e 2010

\begin{tabular}{|c|c|c|c|c|c|c|c|c|c|c|c|c|}
\hline \multirow{3}{*}{$\begin{array}{l}\text { TEMPO DE } \\
\text { RESIDÊNCIA } \\
\text { NO MUNICÍPIO } \\
\text { (EM ANOS) }\end{array}$} & \multicolumn{6}{|c|}{ ANO 2000} & \multicolumn{6}{|c|}{ ANO 2010} \\
\hline & \multicolumn{3}{|c|}{ E. SANTO } & \multicolumn{3}{|c|}{ T. SUL } & \multicolumn{3}{|c|}{ E. SANTO } & \multicolumn{3}{|c|}{ T. SUL } \\
\hline & MF & MRET & $T$ & MF & MRET & $T$ & MF & MRET & $\mathrm{T}$ & MF & MRET & $\mathrm{T}$ \\
\hline $0 \mathrm{Al}$ & 8,00 & 2,84 & 10,84 & 19,10 & 1,43 & 20,53 & 10,22 & 0,58 & 10,80 & 15,01 & 1,08 & 16,09 \\
\hline 2 A 3 & 8,43 & 1,72 & 10,15 & 16,78 & 0,68 & 17,46 & 9,18 & 3,25 & 11,53 & 14,83 & 1,68 & 16,51 \\
\hline 4 A 5 & 6,24 & 1,55 & 7,79 & 5,66 & 1,64 & 7,30 & 6,20 & 1,21 & 7,41 & 10,01 & 1,90 & 11,90 \\
\hline 6 A 7 & 9,47 & 0,60 & 10,07 & 7,30 & 0,68 & 7,98 & 6,17 & 1,23 & 7,41 & 6,88 & 0,79 & 7,67 \\
\hline 8 A 9 & 9,12 & 1,64 & 10,76 & 5,53 & 1,36 & 6,89 & 4,12 & 1,26 & 5,38 & 6,04 & 0,31 & 6,35 \\
\hline $100 \mathrm{U}+$ & 47,85 & 2,54 & 50,39 & 36,63 & 3,21 & 39,84 & 52,11 & 5,38 & 57,48 & 39,31 & 2,17 & 41,48 \\
\hline TOTAL* & 89,11 & 10,89 & 100,00 & 91,00 & 9,00 & 100,00 & 87,99 & 12,01 & 100,00 & 92,08 & 7,92 & 100,00 \\
\hline
\end{tabular}

Fonte: IBGE. Censos demográficos (2000 e 2010). Rio de Janeiro.

Obs.: * - É o que se chama migrante de estoque em qualquer das categorias, i. é, independente do tempo de moradia.

** - Observa-se que há muito pequenas dificuldades de ajustes dos percentuais para os dados correspondentes ao ano de 2010; optamos por apresentar e interpretar os dados tais como estão - não os harmonizando (ajustamentos), pois acreditamos que tais dificuldades não inviabilizam a utilização destas informações disponíveis dos denominados Micro Dados (Migração) do Censo.

A Tabela io discrimina, dentre os Migrantes (total) que possuem menos de ro anos de residência em Tibau do Sul e em Espírito Santo, as suas respectivas faixas etárias nos anos de 2000 e 2010 . Olhando os dados fornecidos pelo Censo 2000 - que dá os números para os migrantes chegados na década de I990 -, claramente se nota que os migrantes que se dirigiram nesta década para o Município de Tibau Sul eram, em mais da metade, pessoas na faixa etária entre os 20 e os 39 anos de idade, indicando forte migração de trabalho. O percentual dos migrantes da década nesta faixa etária (20 a 39 anos) é bem superior no caso de Tibau de Sul quando comparado ao verificado para o Município de Espírito Santo.

Quando se examinam os dados fornecidos pelo Censo do ano 20ro, esta faixa continua a ser bem mais representativa em Tibau do Sul, verificando-se também uma forte presença em Tibau, quando comparado com Espírito Santo, da população na faixa etária seguinte, de 40 a 59 anos. Observa-se ainda que, na faixa de o a I9 anos, há forte superioridade de migrantes em Espírito Santo, fato talvez ligado ao fenômeno intenso de retorno de famílias 
com responsáveis ainda em idade reprodutiva. Os dados migratórios expostos reforçam as descrições anteriormente feitas para as populações residentes nos dois municípios quanto às diferenças nos seus padrões ou perfis etários.

Tabela 10 - Migrantes com menos de 10 anos de residência* nos Municípios de Espírito Santo e Tibau do Sul, segundo a importância relativa (em \%) dos grupos de idade. Anos de 2000 e 2010

\begin{tabular}{lcccc}
\hline \multirow{2}{*}{ GRUPOS DE IDADE } & \multicolumn{2}{c}{ ESPÍRITO SANTO } & \multicolumn{2}{c}{ TIBAU DO SUL } \\
\cline { 2 - 5 } & ANO 2000 & ANO 2010 & ANO 2000 & ANO 2010 \\
\hline 0 A 19 ANOS & 38,31 & 61,13 & 30,24 & 43,24 \\
\hline 20 A 39 ANOS & 36,93 & 25,61 & 50,51 & 36,40 \\
\hline 40 A 59 ANOS & 14,49 & 8,05 & 15,28 & 15,63 \\
\hline 60 ANOS E + & 10,27 & 5,25 & 3,97 & 4,75 \\
\hline TOTAL & 100,00 & 100,00 & 100,00 & 100,00 \\
\hline
\end{tabular}

Fonte: IBGE. Censos demográficos (2000/2010). Rio de Janeiro.

*Obs.: 0 total do estoque de migrantes é depurado para extrair apenas os com até dez anos de residência no Município.

A Tabela I I expõe a descrição dos Migrantes (total) que se dirigiram para Tibau do Sul e para Espírito Santo, respectivamente nas duas décadas (I990 e 2000), segundo a sua distribuição por sexo. Não se podem distinguir diferenças significativas entre os dois fluxos de migrantes que se encaminharam para cada um dos dois municípios quanto ao sexo, e isto acompanha a caracterização, utilizando o cálculo da Razão de Sexo, do conjunto dos residentes em cada uma das unidades municipais.

Tabela 11 - Importância relativa por sexo (em \%) nos Migrantes com menos de 10 anos de residência* nos Municípios de Espírito Santo e Tibau do Sul. Anos de 2000 e 2010

\begin{tabular}{lcccc}
\hline \multirow{2}{*}{ SEXO } & \multicolumn{2}{c}{ ESPÍRITO SANTO } & \multicolumn{2}{c}{ TIBAU DO SUL } \\
\cline { 2 - 5 } & 2000 & 2010 & 2000 & 2010 \\
\hline MASCULINO & 49,13 & 48,03 & 47,11 & 49,22 \\
\hline FEMININO & 50,87 & 51,97 & 52,89 & 50,78 \\
\hline TOTAL & 100,00 & 100,00 & 100,00 & 100,00 \\
\hline
\end{tabular}

Fonte: IBGE. Censos demográficos (2000/2010). Rio de Janeiro.

Obs.: *0 total do estoque de migrantes é depurado para extrair apenas aqueles com até dez anos de residência no município. 
A Tabela 12 descreve as características da instrução formal dos Migrantes (total) que haviam também chegado aos municípios de Tibau e Espírito Santo, respectivamente, na década de 1990 (Censo de 2000) e na década de 2000 (Censo de 20I0). Nesta Tabela se observa com nitidez que os imigrantes que se dirigiram para Espírito Santo na década de I 990 eram majoritariamente caracterizados como situados nos níveis inferiores da disponibilidade da instrução formal, exatamente o oposto para o verificado no Município de Tibau do Sul. Quando se observam os dados fornecidos pelo Censo de 2010, sobre o perfil educacional dos migrantes chegados nos dez anos anteriores, aos dois municípios, a mesma diferenciação é constatada. Merece destaque a forte presença em Tibau do Sul dos migrantes com o Curso Médio Completo e Superior (incompleto ou completo). Tais dados são bem compatíveis com a hipótese da importação dos padrões educacionais de acordo com a natureza das atividades econômicas na área de destino dos fluxos.

Tabela 12 - Migrantes com menos de 10 anos de residência*, respectivamente nos Municípios de Espírito Santo e Tibau do Sul, segundo importância relativa (em \%) do nível de instrução formal que possuem. Anos de 2000 e 2010

\begin{tabular}{lcccc}
\hline \multirow{2}{*}{$\begin{array}{l}\text { NÍVEL DE } \\
\text { INSTRUÇ̃̃ }\end{array}$} & \multicolumn{2}{c}{ ESPÍRITO SANTO } & \multicolumn{2}{c}{ TIBAU DO SUL } \\
\cline { 2 - 5 } & 2000 & 2010 & 2000 & 2010 \\
\hline NÍVEL I & 66,10 & 85,80 & 36,43 & 61,01 \\
\hline NÍVEL II & 29,78 & 8,21 & 39,08 & 14,69 \\
\hline NÍVEL III & 3,2 & 5,98 & 24,68 & 24,30 \\
\hline NÍVEL ND & 2,34 & - & 0,91 & 0,00 \\
\hline
\end{tabular}

Fonte: IBGE. Censos demográficos (2000/2010). Rio de Janeiro.

Obs.: *0 total do estoque de migrantes é depurado para extrair apenas aqueles com até dez anos de residência no município.

** Nível I: Sem instrução e fundamental incompleto (o a 3 anos de estudo).

Nível II: Fundamental completo e médio incompleto (4 a 10 anos de estudo).

Nível III: Médio completo e superior incompleto ou completo (com 11 ou mais anos de estudo). Nível ND: Não determinado.

Com exceção dos dados para T. do Sul em 2010, as demais totalizações dos percentuais apresentam pequenas diferenças em relação a 100\%. Ex.: E. Santo (2000: 101,42\%; 2010: 99,99); T. do Sul (2000:101,10). Omitimos então as totalizações dos percentuais. As inconsistências indicadas, acreditamos, não alteram a capacidade sugestiva geral dos dados.

A Tabela I 3 apresenta a Taxa de Imigração Estrangeira para os dois municípios que estão tendo os seus perfis demográficos comparados. O que chama a atenção, quanto à presença dos estrangeiros, comparativamente entre as duas 
unidades municipais, é em primeiro lugar a total ausência deles no Município de Espírito Santo, tanto no ano de 2000 quanto no ano de $20 \mathrm{IO}$. Em segundo lugar, deve-se observar que a presença dos estrangeiros, já constatada na destinação turística Tibau do Sul para o ano de 2000 , é ela significativamente crescente, como indica o registro dos mesmos para o ano de $20 \mathrm{IO}$.

Neste último município, Tibau, no ano de 2000 , o Censo constatou a residência de 34 indivíduos (Taxa de Imigração Estrangeira, o,44\%) que não eram brasileiros natos; é presença modesta, resultante da fase de acelerado desenvolvimento da destinação, mas significativa, vez que ela pode sem dúvida ser interpretada como um efeito estrutural sobre o perfil demográfico do resort. Reforçador desta observação é que, dez anos depois, os não brasileiros natos residentes serão 22 I pessoas, que é o total deles (estrangeiros) registrado em 2000 multiplicado 6,5 vezes. A Taxa de Imigração, por seu lado, vai ser multiplicada 4,4 vezes, passando de 0,44 em 2000 para I,94\% no ano de 20 Io. Isto revela o crescimento no fluxo dos estrangeiros, crescimento claramente associado às fases de desenvolvimento (subfase alta) e consolidação da função turística em Tibau do Sul. À proporção que a destinação em foco se foi consolidando e os estabelecimentos de hospedagem ganhando escala e institucionalização, a destinação tendeu a acelerar a sua internacionalização no quesito residente. A presença dos residentes estrangeiros cresce muito mais que a dos residentes nascidos no Brasil.

Tabela 13 - Taxa de Imigração Estrangeira (TIExt)* (em \%) nos Municípios de Espírito Santo e Tibau do Sul nos anos de 2000 e 2010

\begin{tabular}{|ccccc|}
\hline & \multicolumn{2}{c}{ ANO 2000} & \multicolumn{2}{c|}{ ANO 2010} \\
\hline & E. SANTO & T. DO SUL & E. SANTO & T. DO SUL \\
\hline RESIDENTES NÃO BRASILEIROS NATOS & - & 34 & - & 221 \\
\hline TIEXTRANGEIRA & 0 & 0,44 & 0 & 1,94 \\
\hline
\end{tabular}

Fonte: IBGE. Censos demográficos (2000/2010). Rio de Janeiro.

*OBSERVAÇÕES: População residente de não brasileiros natos compreende as pessoas nascidas em outros países e residindo no determinado município brasileiro; inclui os não naturalizados e os naturalizados. A Taxa de Imigração Estrangeira (ou de Residentes Não Brasileiros Natos) é obtida mediante a fórmula: Não Brasileiros Nato Residentes/População Total Residente x 100. Dos 221 não brasileiros natos residentes no Município de Tibau do Sul no ano de 2010, apenas 28 deles (13\%) estavam naturalizados.

$\mathrm{Na}$ Tabela I 4 estão discriminadas as épocas de chegadas dos volumes dos brasileiros não natos que estavam residindo em 2010 no Município de 
Tibau do Sul. Como a presença dos estrangeiros como residentes somente começa a ter lugar a partir dos anos de I990, aceitamos que o subperíodo "até 2000" significa de fato a década de r990. Olhando-se os decênios, o período de maior importância de chegadas para os estrangeiros que residiam no município em 20I0, foi o compreendido entre $200 \mathrm{I}$ a 2010 , mas sem que as chegadas acontecidas até o ano de 2000 deixem de ser significativas. Evidentemente que existe certo fator que poderia ser chamado de "fator de tempo de permanência em si". É isto que talvez faça com que, ao examinarmos os dois quinquênios da última década, o mais recente, isto é, o de 2006 a 2010 , seja mais expressivo.

Tabela 14 - Importância relativa (em \%) do período no qual fixaram residência no Brasil os Residentes Não Brasileiros Natos registrados no ano de 2010 no Município de Tibau do Sul

ATÉ 2000 (A) DE 2001 A 2005 (B) DE 2006 A 2010 (C) APENAS 2001/2010 (B+C) TOTAL $(A+B+C)$

$\begin{array}{llll}31,7 & 29,9 & 38,4 & 68,3\end{array}$

Fonte: IBGE. Censo demográfico (2010). Rio de Janeiro.

A Tabela 5 identifica, para os Municípios de Tibau do Sul e Espírito Santo, de acordo com os resultados dos dois últimos censos, o de 2000 e o de 20 Io, a unidade da federação (Estado) onde nasceram os residentes natos no Brasil - todos eles, sejam migrantes ou não migrantes.

Então, quando observamos o local de nascimento destes residentes nos dois municípios que estão sendo objeto da comparação, nota-se que no ano de 2000 a presença dos nascidos no próprio Estado do Rio Grande Norte é praticamente a mesma para ambas as unidades municipais. Entretanto, dez anos depois - no ano de 2010 -, a presença dos residentes nascidos no próprio Estado do Rio Grande do Norte declina significativamente para Tibau do Sul; e mesmo aumenta, ainda que muito pouco, para o caso do Município de Espírito Santo. O município resort turístico revela na última década uma maior capacidade de atração de imigrantes oriundos dos outros estados da federação, e também internacionais como já antes comentado e evidenciado.

São por ordem de importância - excluindo-se o próprio Estado do R. G. do Norte, claro -, respectivamente, os imigrantes nascidos na Paraíba $(3,75 \%)$, Rio de Janeiro (0,96\%), São Paulo (0,25\%) e Pernambuco (0,20\%) as quatro unidades federativas de nascimento que se podem destacar, para o ano de 2000 , em Espírito Santo, e esta hierarquia mantém-se segundo 
os dados censitários para o ano de 20Io. Portanto, o perfil de origem do migrante, quanto à unidade da federação de nascimento, não é alterado neste último município, caso se observe o estoque dos residentes nascidos noutros estados registrados pelos dois censos, o de 2000 e o de 20 Io.

Observando-se o padrão para Tibau do Sul, entretanto, nota-se que para o ano de 2000 as origens mais importantes - excetuando-se, claro, o próprio RN - foram os Estados da Paraíba, São Paulo, Rio de Janeiro, e Estados do NO/CO/DF/ES, seguido de Estados da Região Sul, Bahia e Pernambuco (esse com $0,40 \%$ ). O posicionamento de São Paulo, do DF e dos Estados do Sul sugere existir diferenciação de padrões de origem para o ano de 2000, quando comparado ao padrão para o Município de Espírito Santo. Acredita-se que o padrão de origem do estoque para o município resort, padrão registrado no ano de 2000 , ainda não esteja tão afetado pela expansão da função turística como estará dez anos depois, em 20 Io.

Então, olhando os dados de dez anos depois para a destinação turística (Tibau do Sul), ano de 20 ıо, o Estado da Paraíba se mantém na primeira posição, mas Pernambuco passa à segunda, seguido por São Paulo e Rio de Janeiro. Destaca-se ainda no caso de Tibau do Sul, comparando-se com os dados de 2000, a crescente presença de residentes nascidos em Estados do Sul do Brasil, e na Bahia e em Alagoas, estes dois últimos e a Região Sul com tradição de forte oferta turística litorânea. Pode-se crer que esta geografia dos fluxos reflita as relações de Tibau com zonas com características de exportar trabalhadores mais qualificados e investidores do setor de turismo, lazer e entretenimento. 
Tabela 15 - Importância (em \%) da unidade da federação de nascimento dos Residentes Brasileiros Natos e da população dos Brasileiros Natos em relação ao total da População Residente nos Municípios de Espírito Santo e Tibau do Sul, para os anos de 2000 e 2010

\begin{tabular}{lcccc}
\hline \multirow{2}{*}{$\begin{array}{l}\text { ESTADO OU REGIÃO DE } \\
\text { NASCIMENTO NO BRASIL }\end{array}$} & \multicolumn{2}{c}{ ANO DE 2000} & \multicolumn{2}{c}{ ANO DE 2010 } \\
\cline { 2 - 5 } RIO G. DO NORTE & 94,60 & 94,84 & 95.22 & 89,66 \\
\hline PARAÍBA & 3,75 & 1,21 & 1,80 & 2,23 \\
\hline RIO DE JANEIRO & 0,96 & 0,65 & 1,32 & 1,66 \\
\hline SÃO PAULO & 0,25 & 0,81 & 0,91 & 1,69 \\
\hline PERNAMBUCO & 0,20 & 0,40 & 0,42 & 2,20 \\
\hline CEARÁ & 0,14 & 0,10 & 0,00 & 0,12 \\
\hline BAHIA & 0,00 & 0,47 & 0,07 & 0,43 \\
\hline PIAUÍ & 0,00 & 0,00 & 0,05 & 0,05 \\
\hline REGIÃO SUL & 0,00 & 0,48 & 0,00 & 0,86 \\
\hline DF, E. SANTO, REGIÕES CO E NO & 0,07 & 0,57 & 0,19 & 0,26 \\
\hline ALAGOAS & 0,00 & 0,04 & 0,00 & 0,36 \\
\hline SERGIPE & 0,04 & 0,00 & 0,00 & 0,04 \\
\hline MINAS GERAIS & 0,00 & 0,09 & 0,05 & 0,21 \\
\hline SEM ESPECIFICAÇÃO & 0,00 & 0,00 & 0,00 & 0,26 \\
\hline POP. DE RESIDENTES BRAS. NATOS & 100,00 & 99,56 & 100,00 & 98,06 \\
\hline
\end{tabular}

Fonte: IBGE. Censos demográficos (2000/2010). Rio de Janeiro.

Obs.: Os percentuais de origem por Estados são calculados em relação ao total de residentes brasileiros natos.

\section{CONCLUSÕES}

Pode-se afirmar que a população no município que experimenta o processo de desenvolvimento e consolidação da função turística exibe nítido rejuvenescimento demográfico. O número dos residentes cresceu com rapidez em decorrência do influxo das migrações com perfil marcadamente concentrado nas idades de trabalho e reprodução. 
A migração é claramente orientada para o trabalho, com menor importância relativa dos migrantes de retorno em relação aos forasteiros. Os migrantes são em geral indivíduos nascidos em outros municípios e unidades da federação, isso conduzindo, pelas exigências da seletividade de inserção no mercado de mão de obra dos serviços turísticos, à importação de padrões educacionais. A seletividade orienta as origens geográficas nacionais dos migrantes, reforçando aquelas origens associadas à tradição de formação de mão de obra e exploração da atividade turística. O município passa a progressivamente atrair migrantes nascidos em outros países, aumentando na sua população residente a presença dos estrangeiros.

A fase de desenvolvimento da destinação exibe altas taxas de crescimento da população residente com base no influxo migratório, e isto parece ser o sinal mais impressivo da fase. A fase de consolidação do resort parece se expressar sobremaneira por uma desaceleração no crescimento da população local, a fixação de um diferenciado perfil educacional na sua população e um aumento significativo na presença dos estrangeiros e nacionais oriundos de locais com tradição de oferta de serviços turísticos.

O Quadro 2, a seguir, sumariza analiticamente as conclusões extraídas da observação do material estatístico demográfico.

Quadro 2 - Esquema Sintético Conclusivo da comparação dos Perfis Demográficos e Migratórios entre os Municípios de Tibau do Sul e Espírito Santo na perspectiva da diferenciação produzida pelo Ciclo da Destinação Turística no M. de Tibau do Sul

\begin{tabular}{|c|c|}
\hline VARIÁVEL & CONCLUSÕES \\
\hline $\begin{array}{l}\text { CRESCIMENTO } \\
\text { POPULACIONAL }\end{array}$ & 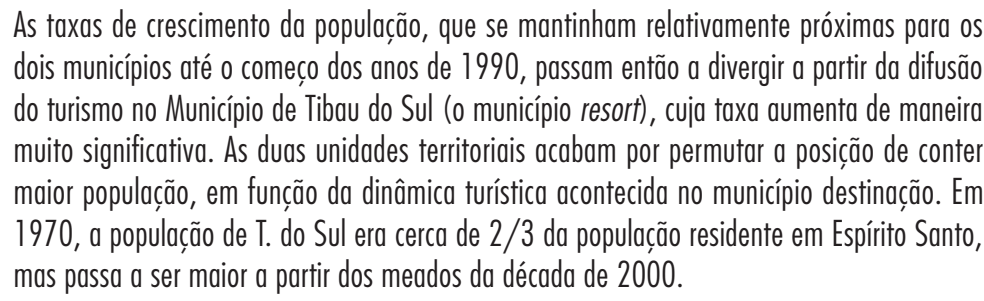 \\
\hline RAZÃO DE SEXO & $\begin{array}{l}\text { Não são registradas diferenças significativas entre os padrões para cada um dos dois munić- } \\
\text { pios. Foi apenas no ano de } 1996 \text { que a Razão de Sexo foi mais elevada para o Município de } \\
\text { Tibau do Sul, isto talvez decorrente das obras da construcãa civil hoteleira em Tibau. }\end{array}$ \\
\hline
\end{tabular}




\begin{tabular}{|c|c|}
\hline VARIÁVEL & CONCLUSÕES \\
\hline $\begin{array}{l}\text { TDG, TDI E TDINF } \\
\text { (TAXAS DE } \\
\text { DEPENDÊNCIA GERAL, } \\
\text { DE IDOSOS E INFANTIL) }\end{array}$ & $\begin{array}{l}\text { A Taxa de Dependência Geral (TDG) cai mais suavemente no caso do Município de Espírito } \\
\text { Santo, desde 1991 - ano em que era menor que a de Tibau - até o ano de } 2010 \text {. Neste } \\
\text { último ano (2010), a mencionada taxa se reduz significativamente para ambos os municípios } \\
\text { em relação ao padrão de 1991. A população de Tibau do Sul exibe um padrão etário mais } \\
\text { centrado na faixa de } 14 \text { a } 65 \text { anos. A Taxa de Dependência de Idosos (TDI) é severamente } \\
\text { mais alta no caso do Município de Espírito Santo. A população de Tibau é muito centrada na } \\
\text { faixa de reproducão. Decorre daí ser compreensível que a Taxa de Dependência Infantil em } \\
\text { Espírito Santo não seja tão mais alta que a verificada em Tibau. }\end{array}$ \\
\hline $\begin{array}{l}\text { CARACTERIZAÇÃO } \\
\text { EDUCACIONAL }\end{array}$ & $\begin{array}{l}\text { A variável nível de instrução formal é extremamente significativa na diferenciação de padrões } \\
\text { demográficos ou perfis entre os dois municípios. A participação da faixa de menor instrução é } \\
\text { acentuadamente mais alta para a população com } 10 \text { anos ou mais no Município de Espírito } \\
\text { Santo. Quando, contudo, se trata das faixas que somadas incluem a população com curso } \\
\text { de nível médio completo ou mais (inclusive curso superior seja completo ou incompleto), a } \\
\text { importância destas duas últimas faixas somadas para Tibau do Sul representa mais que o } \\
\text { dobro do verificado para o Município de Espírito Santo. Certamente se verifica um fenômeno } \\
\text { da importaçãa de padrões educacionais externos, evento reconhecido nas áreas que recebem } \\
\text { forte influxo de imigrantes para funções de serviços e relembra a natureza seletiva da expe- } \\
\text { riência migratória. Tal diferenciação de padrão, entre as duas unidades municipais, resulta da } \\
\text { acumulaçãa migratória ao longo das duas décadas examinadas. }\end{array}$ \\
\hline $\begin{array}{l}\text { IMPORTÂNCIA DA } \\
\text { MIGRAÇ̃̃O NA } \\
\text { COMPOSIC̦̃̃O DA } \\
\text { POPULAÇÃO RESIDENTE }\end{array}$ & $\begin{array}{l}\text { Dados para } 0 \text { ano de } 2000 \text { apontam a Taxa de Não Migrantes bem aproximada para os dois } \\
\text { municípios. Entretanto, para } 0 \text { ano de } 2010 \text {, fruto certamente do influxo maior de imigrantes } \\
\text { em Tibau, a importância dos migrantes é sensivelmente maior para } 0 \text { Município de Tibau do } \\
\text { Sul. As Migrações de Retorno aumentam para os dois municípios, quando se compara os dados } \\
\text { registrados para } 0 \text { ano de } 2000 \text { e de } 2010 \text {. }\end{array}$ \\
\hline $\begin{array}{l}\text { PERIOODOS DE } \\
\text { CHEGADA DOS FLUXOS } \\
\text { MIGRATÓRIOS }\end{array}$ & $\begin{array}{l}\text { Examinando os dados coletados pelo Censo de 2000, observa-se com clareza que a época } \\
\text { de chegada do estoque existente de migrantes no Município de Tibau do Sul naquele ano, foi } \\
\text { muito significativa nos anos compreendidos entre } 1998 \text { a } 2000 \text {, fase de intensa aceleração } \\
\text { na expansão da destinação turística. Os migrantes com menos de dez anos, isto é, chegados } \\
\text { durante a década de 1990, a da expansão turística em Tibau do Sul, eram também sensivel- } \\
\text { mente mais importantes neste Município que no Município de Espírito Santo. Ao lado disto, a } \\
\text { Migração de Retorno revelou-se mais significativa em Espírito Santo na década 1991/2000. } \\
\text { Foram os Migrantes (não nascidos no município onde residiam) os responsáveis pela dinâmica } \\
\text { migratória em Tibau do Sul, especialmente nos últimos anos da década de 1990. Dados de } \\
2010 \text { indicam que a força das migrações mais recentes, isto é, as acontecidas entre } 2001 \\
\text { e } 2010 \text {, para o total do estoque dos Migrantes, continua a ser maior para Tibau do Sul, em } \\
\text { comparação com o Município de E. Santo. A expressividade dos "recentes", no total do esto- } \\
\text { que de Migrantes, é ainda mais acentuada em } 2010 \text { que no caso do ano de } 2000 \text {. }\end{array}$ \\
\hline
\end{tabular}




\begin{tabular}{|c|c|}
\hline VARIÁVEL & CONCLUSÕES \\
\hline $\begin{array}{l}\text { OS MIGRANTES } \\
\text { SEGUNDO SUAS } \\
\text { FAIXAS ETÁRIOS }\end{array}$ & $\begin{array}{l}\text { Nos dados do Censo } 2000 \text { (Migrantes chegados na década de 1990) evidencia-se que os } \\
\text { Migrantes que se dirigiram para o Município de Tibau do Sul eram na sua maioria pessoas na } \\
\text { faixa etária dos } 20 \text { aos } 39 \text { anos, indicando forte migração de trabalho. A importância desta } \\
\text { faixa etária nos Migrantes em Tibau é bem superior ao verificado para Espírito Santo. Quando } \\
\text { se examina os dados fornecidos pelo Censo do ano de 2010, esta faixa continua a ser bem } \\
\text { mais significativa em Tibau do Sul, verificando-se também uma forte presença em Tibau, } \\
\text { quando comparada com Espírito Santo, da população na faixa etária seguinte, de } 40 \text { a } 59 \\
\text { anos. Observa-se ainda que, na faixa de } 0 \text { a } 19 \text { anos, há forte superioridade de migrantes em } \\
\text { Espírito Santo, fato talvez ligado ao fenômeno intenso de retorno de famílias com responsá- } \\
\text { veis ainda em idade reprodutiva. Há, portanto, diferenciais etários significativos nos migrantes } \\
\text { que se dirigiram para cada um dos dois municípios. }\end{array}$ \\
\hline $\begin{array}{l}\text { OS MIGRANTES } \\
\text { SEGUNDO O SEXO }\end{array}$ & $\begin{array}{l}\text { Observa-se que não há diferenças significativas entre os fluxos de migrantes que se dirigiram } \\
\text { para cada um dos dois municipios quanto ao sexo. Isto é compatível com os dados da caracte- } \\
\text { rização por sexo para o conjunto dos residentes em ambos os municípios. }\end{array}$ \\
\hline $\begin{array}{l}\text { OS MIGRANTES } \\
\text { SEGUNDO NIVEL } \\
\text { DE INSTRUÇÃO }\end{array}$ & $\begin{array}{l}\text { Os Migrantes que se dirigiram para Espírito Santo ao longo da década de } 1990 \text { eram majorita- } \\
\text { riamente caracterizados como situados na categoria de instrucão menor. Exatamente o oposto } \\
\text { era verificado no Município de Tibau do Sul. Nos dados do Censo de 2010, sobre o perfil } \\
\text { educacional dos migrantes chegados nos dez anos anteriores aos dois municípios, o mesmo } \\
\text { padrão se mantém, merecendo destaque a forte presença em Tibau do Sul dos migrantes com } \\
\text { Curso Médio Completo e Superior (incompleto ou completo). Tais dados são bem compatíveis } \\
\text { com a hipótese da importação dos padrões educacionais de acordo com a natureza das ativi- } \\
\text { dades econômicas na área de destino (seletividade). }\end{array}$ \\
\hline $\begin{array}{l}\text { BRASILEIROS NATOS } \\
\text { SEGUNDO A UNIDADE } \\
\text { DA FEDERAC̦̃̃O DE } \\
\text { NASCIMENTO }\end{array}$ & $\begin{array}{l}\text { No ano de 2000, a presença dos nascidos no próprio Estado do Rio Grande Norte é pratica- } \\
\text { mente a mesma para ambas as unidades municipais. Contudo, vendo o ano de 2010, a pre- } \\
\text { sença dos indivíduos nascidos no próprio Estado declina significativamente para Tibau do Sul, } \\
\text { e mantém-se praticamente a mesma para o Município de Espírito Santo. Após a importância } \\
\text { do próprio Estado do R. G. do Norte, o padrão das origens (por ordem de relevância: PB, RJ, } \\
\text { SP e PE) se mantém para } 0 \text { ano de } 2010 \text { em Espírito Santo. No padrão para Tibau do Sul, } \\
\text { entretanto, observa-se que para o ano de } 2000 \text { as origens mais importantes - excetuando-se } \\
\text { o próprio RN - foram PB, SP, RJ, e Estados do N0/CO/DF/ES, seguindo-se os Estados do } \\
\text { Sul, BA e PE. } 0 \text { posicionamento de SP, do DF e dos Estados do Sul sugere uma diferenciação } \\
\text { de padrões de origem já para o ano de } 2000 \text {. Dez anos depois, ano de } 2010 \text {, a Paraíba se } \\
\text { mantém na primeira posição; contudo, Pernambuco passa à segunda posição, seguido por } \\
\text { São Paulo e Rio de Janeiro. Destaca-se, comparando-se com os dados de } 2000 \text {, a crescente } \\
\text { presença no Município de Tibau de residentes nascidos em Estados da Região Sul do país, na } \\
\text { Bahia e em Alagoas, estes dois últimos com tradição de forte oferta turística litorânea, o que } \\
\text { supõe interações de força de trabalho e investimentos. }\end{array}$ \\
\hline
\end{tabular}




\begin{tabular}{|c|c|}
\hline VARIÁVEL & CONCLUSÕES \\
\hline $\begin{array}{l}\text { MIGRANTES } \\
\text { ESTRANGEIROS } \\
\text { (NÃO BRASILEIROS } \\
\text { NATOS) }\end{array}$ & $\begin{array}{l}\text { Total ausência de Não Brasileiros Natos no Município de Espírito Santo, tanto no ano de } 2000 \\
\text { quanto no ano de } 2010 \text {, e a presença progressivamente maior dos mesmos no Município de } \\
\text { Tibau do Sul (2000 e 2010). Neste município, no ano de 2000, constatou-se a presença } \\
\text { de } 34 \text { indivíduos (0,44\%) que não haviam nascido no Brasil, presença ainda bem pequena, } \\
\text { mas diferenciadora do seu padrão migratório comparativamente a E. Santo. Dez anos depois, } \\
\text { aquela presença é quase quintuplicada, passando para } 221 \text { pessoas ou 1,94\% da população } \\
\text { total dos residentes. Isto revela o crescimento do fluxo dos migrantes internacionais, evento } \\
\text { associado à expansão da função turística em Tibau do Sul. }\end{array}$ \\
\hline $\begin{array}{l}\text { PERIODOS DE } \\
\text { CHEGADA DOS FLUXOS } \\
\text { MIGRATÓRIOS DE NÃO } \\
\text { BRASILEIROS NATOS }\end{array}$ & $\begin{array}{l}\text { Examinando-se os decênios, o período de chegada ao Brasil de maior importância para os } \\
\text { Não Brasileiros Natos que ainda residiam no Município de Tibau do Sul no ano de } 2010 \text {, é } \\
0 \text { de } 2001 \text { a 2010, mas sem que as chegadas acontecidas até } 0 \text { ano de } 2000 \text { deixem de } \\
\text { ser reconhecidas como significativas. Comparando-se apenas os dois quinquênios da última } \\
\text { década, conclui-se que o de } 2006 \text { a } 2010 \text { é o mais importante. }\end{array}$ \\
\hline
\end{tabular}

\section{REFERÊNCIAS}

AGARWAL, S., (I997). The resort cycle and seaside tourism: an assessment of its applicability and validity. Tourism Management, v. I8, n. 2, p.65-73.

AITKEN, C.; HALL, M. (2000). Migrant and foreign skills and their relevance to the tourism industry. Tourism Geographies, 2(I):67-86.

ANDRADE, M. C. de. (I957). Os rios do açúcar do Nordeste Oriental: o Rio Mamanguape. Recife: Instituto Joaquim Nabuco de Pesquisas Sociais.

ANDRADE, G. O. de. (I 959). Os rios do açúcar do Nordeste Oriental: o Rio Paraíba do Norte. Recife: Instituto Joaquim Nabuco de Pesquisas Sociais.

ARAÚJO, L. M. (20I2). Políticas públicas de turismo e território em regiões periféricas. In: Castilho, C.; SELVA, V. (org.). Turismo, políticas públicas e gestão dos ambientes construídos. Recife: Editora da Universidade Federal de Pernambuco, p.53-72.

ARAÚJO, L.; BRAMWELL, B. (2002). Partnership and regional tourism in Brazil. Annals of Tourism Research, v. 29, n. 4, p. II38-I I 64.

ARAUJO, L.; DREDGE, D. (2012). Tourism development, policy and planning in Brazil. Tourism in Brazil: environment, management and segments. London: Routledge, p. I 6-29.

BARROS, N.C. de (2002a). Análise regional e destinações turísticas: possibilidades teóricas e situações empíricas em G. do Turismo. Turismo: visão e ação, Camboriú, v.4, n. I I, p. 9-32. 
. (2002b). Seaside tourist destination area in North East Brazil. In: THE ANNUAL MEETING OF THE ASSOCIATION OF AMERICAN GEOGRAPHERS, Los Angeles. . (2003). O rejuvenescimento da região turística por expansão geográfica e redistribuição territorial das funções: a destinação turística de Pipa, litoral do Nordeste do Brasil. Revista Geográfica, Instituto Panamericano de Geografia e História, México, n. I33, p.73-90.

- (2005). Expansão turística, dinâmica espacial e sustentabilidade das destinações no litoral do Nordeste do Brasil. Turismo: visão \& ação, Camboriú, v. 7, n.2, p. 24 I-256. . (2009). Por que as destinações turísticas no Nordeste do Brasil não declinam: uma interpretação geográfica. Recife: Editora da Universidade Federal de Pernambuco. BELL, M.; WARD, G. (2000). Comparing temporary mobility with permanent migration. Tourism Geographies, 2(I): 87-I07.

BNB.PRODETUR (20I2) (site: www.bnb.gov.br).

BOTERRIL, D.; HAVEN, C.; GALE, T (2002). A survey of doctoral theses accepted by universities in the UK and Ireland for tourism studies, I990-I999. Tourist Studies, v. 2, n. 3, p. 283-3II.

BRITO, F. (2009). As migrações internas no Brasil: um ensaio sobre os desafios teóricos recentes. B. Horizonte. In: VI ENCONTRO NACIONAL SOBRE MIGRAÇÕES, ABEP. BUTLER, R. W. (I980). The concept of a tourist area cycle of evolution: implications for management of resources. Canadian Geographer, v.24, n. I, p. 5-I 2.

. (2006). The tourism area life cycle: applications and modifications. Clevedon, England: Channel View Publications, volume I.

BUTLER, R. (2009). Tourism in the future: Cycles, waves or Wheels? Futures, v. 4 I, n.6, p. 346-352.

CAMPOS, M.; BARBIERI, A.; CARVALHO, J. (2007). Migração e Previdência Social no Brasil entre I980 e 2000. In: ENCONTRO NACIONAL SOBRE MIGRAÇÕES, ABEP. CASAL, Manuel Aires do. (I976). Corografia Brasílica. Belo Horizonte/São Paulo: Itatiaia/Edusp.

CHALKITI, K. C. (2007). Mass Tourism: diversification and sustainable development in Southern Europe. Tourisms: an international Multidisciplinary Journal of Tourism, v.2, n.I, p.I63-I 66.

CHOY, D. (I992). Life Cycle Model for Pacific Islands Destinations. Journal of Travel Research, v. 30, p.26-3I.

CHRISTALLER, W. (I963). Some considerations of tourism location in Europe. Regional Science Association Papers, n. I2, cit in: BUTLER, I980, op.cit.

COLTMAN, M. M. (I997). Introduction to Travel and Tourism. New York: Van Nostrand Reinhold, I989. In: GONÇALVES \& ÁGUAS. 
COOPER, C. (I994). The destination lifecycle: un update. In: SEATON, A.V., JENKINS, C.L. at al., eds. Tourism: the State of the Art. Chichester, West Sussex: John Wiley \& Sons, p.340-346, cit. in: WILKINSON, I996, op. cit.

CONWAY, D.; POTTER, R. (2007). Caribbean Transnational Return Migrants as Agents of Change. Geography Compass, I/I, p.25-45.

CRUZ, R. C. (2003). Introdução à Geografia do Turismo. São Paulo: Roca.

DANIELS, P. (I993). Service Industries in the World Economy. London: Institute of British Geographers (IBG)/Blackwell.

DEFERT, P. (2003). Le Taux de Fonction Touristique: mise au point et critique. Cahiers du Tourism, C-I3, CHET, Aix-en-Provence, cit por PEARCE.

DOUGLAS, N. (I 997). Applying the lifecycle model to Melanesia. Annals of Tourism Research, v. 24, n. I, p. I-22.

GARROD, B.; FYALL, A. (I998). Beyond the rhetoric of sustainable tourism? Tourism Management, v. I9, n. 3, p.I99-2I2.

GOMES, P. (I995). O conceito de Região e sua discussão. In: CASTRO, I.; GOMES, P.; CORREA, R. Geografia: conceitos e temas. Rio de Janeiro: Bertrand, p.49-76.

GONÇALVES, V.; ÁGUAS, P. (I997). The concept of life cycle: an application to the tourist product. Journal of Travel Research, v. 36, n.2, p. I 2-22.

GUEDES, M. Z. (2005). O papel das aposentadorias e benefícios da previdência na dinâmica socioeconômica dos Municípios de Equador e Parelhas, RN. Natal. Dissertação (Mestrado em Geografia) - Departamento de Geografia, Universidade Federal do Rio Grande do Norte.

HALL, C.; WILLIAMS, A. (2002). Tourism, migration, circulation and mobility: the contingencies of time and place. In: Tourism and Migration: new relationship between production and consumption. Netherlands: Kluwer Academic Publishers, p. I-52.

HARRISON, L; HUSBANDS, W. eds. (I996). Practicing responsible tourism: international case studies in Tourism planning, policy and development. New York: John Wiley \& Sons.

HERNANDEZ, J.; LEON, C. (2007). The interactions between natural and physical capitals in the tourist lifecycle model. Ecological Economics, v. 62, n.I, p.I84-I93, April. IBGE. Censos Demográficos do Brasil (I970, I980, I99I, 2000 e 2010). Rio de Janeiro. . Contagem de População do Brasil (I 996, 2007). Rio de Janeiro. . (20I2). Pesquisa de meios de hospedagem ano 20I I. Rio de Janeiro.

JOHNSTON, C. (200I). Shoring the foundations of the destination life cycle model: part I (ontological and epistemological); part 2 (a case study of Khona, Hawai'i Island). Tourism Geographies, v.3, n. I, 2, p. 2-28, I3 5-I 64 .

JUANEDA, C.; SASTRE, F. (I999). Balearic Islands tourism: a case study in demographic segmentation. Tourism Management, v. 20, n.4, p.549-5 52. 
LENCIONI, S. (2003). Região e Geografia. São Paulo: Edusp.

LIKORISH, J.; KERSHAW, A. (I958). The Travel Trade. London: Practical Press, cit. in CHOY, I992, op.cit.

LIU, A.; WALL, G. (2006). Planning tourism employment: a developing country perspective. Tourism Management, 27, p.I 59-I70.

LOZATO-GIOTART, J. (I993). Géographie du tourisme. Paris: Masson.

LUNDGREN, J. (1982). The tourist frontier of Nouveau Quebec: functions and regional linkages. Tourist Review, v. 37, n.2, p. IO-I6, I982, cit. in: PEARCE, 2003, op. cit.

MASSEY, D. (2005). For Space. London: Sage Publications.

MELO. M. L. de. (I958). Aspectos do "habitat" rural no Nordeste do Brasil. Anais da Associação dos Geógrafos Brasileiros, São Paulo, v.X, tomo I, p.22 I-266.

MIOSSEC, J. (I976). Elements pour une théorie de l' espace touristique. Les Cahiers du Tourisme, Aix-en-Provence, n. C 36, cit. in: PEARCE, 2003, op. cit.

MOORE, W.; WHITEHALL, P. (2005). The tourism area lifecycle and regime switching models. Annals of Tourism Research, v. 32, n. I, p. I I 2-I 26.

MOURA, H. (org). ( I980). Migrações internas: textos selecionados. Fortaleza: BNB, 2 vols.

NORONHA, R. (I976). Review of the sociological literature on tourism. Washington: The World Bank.

OJIMA, R.(2012). As migrações recentes no Rio Grande do Norte. Cadernos de Estudos Sociais da Fundação Joaquim Nabuco, Recife, v.26, n.2, p.I47-I 53.

PAGNATO, F.; BECKER, O. (2007). Dinâmica migratória na capital do petróleo. In: ENCONTRO NACIONAL SOBRE MIGRAÇÕES DA ABEP.

PANIÁGUA, A. (2002). Urban.-rural migration, tourism entrepreneurs and rural restructuring in Spain. Tourism Geographies, v.4, n.4, p.349-37I.

PEARCE, D. (2003). Geografia do Turismo: fluxos e regiões no mercado de viagens. São Paulo: Aleph.

PLANE, D.; ROGERSON, P. (I 994). The geographical analysis of population. New York: J. W. Sons.

PLOG, S. (I973). Why destination areas rise and fall in popularity. Cornell Hotel and Restaurant Administration Quarterly, p.I3-16, November.

PMT (Prefeitura Municipal de Tibau do Sul) (2006) Listas de hotéis e pousadas (vários anos). Tibau do Sul.

SALVA-TOMÀS, P. (I996). Las implicaciones socioculturales del turismo en el mar Mediterraneo. In: LEMOS, A. ed. Turismo: impactos socioambientais. S. Paulo: Hucitec, p.I87-206.

SALVÀ-TOMÀS, P. (2002). Tourism development and foreign immigration in Balearic Islands. Révue européenne des migrations internationals, v.I 8, n.I, p.I-I 4 . 
SILVA, L. (2005). Reconfiguração do Norte Fluminense a partir dos anos 70: a chegada do petróleo e suas consequências na dinâmica do crescimento regional. ENCONTRO DA ABEP, R. de Janeiro.

SINGER, P. (I980). Migrações internas: considerações teóricas sobre seu estudo. In: MOURA, H. op. cit. pp...2I 7-244.

STANBACK, T.; BEARSE, P.; NOYELLE, T.; KARASEK, R. (I983). Services: The New Economy. New Jersey: Rowman \& Allanheld Publishers.

STANSFIELD, C. (I970) The development of modern seaside resort. Parks and Recreation, v. 5, n.IO, p. I4-I7; 43-46.

SZIVAS, E.; RILEY, M. (2002). Labour mobility and tourism in the post 1989 transition in Hungary. In: HALL, C.; WILLIAMS, A. Tourism and Migration: new relationship between production and consumption. Netherlands: Kluwer Academic Publishers, p. 53-72. SZIVAS, E.; RILEY, M.; AIREY, D. (2003). Labor mobility into tourism. Annals of Tourism Research, v.3O, n.I, p.64-76.

THUROT, J. (I973). Les Tourisme tropical Balnéaire: le modele caraibe et ses extensions. Tese au Centre d'Études du Tourisme, Aix-en-Provence, cit. In: PEARCE, 2003, op.cit. TOURISM GEOGRAPHIES. (2000). Vol. 2, n. I, February (special number on Tourism \& Migration).

TSIAKALI, K. (2008). The tourism area lifecycle. Tourisms: an international Multidisciplinary Journal of Tourism, v.3, n.I, p.200-203.

TURNER, L.; ASH, J. (I976) The golden hordes. New York: St. Martin Press.

WHITTLESEY, D. (1929). Sequent Occupancy. Annals of the Association of American Geographers, v.I9, p.I62-165.

WILKINSON, P. (1996). Graphical Images of the Commonwealth Caribbean. In: HARRISON; HUSBANDS, p.r6-40, op.cit.

WILLIAMS, A.; HALL, C. (2000). Tourism and migration: new relationship between production and consumption. Tourism Geographies, v. 2, n.I, p. 5-27.

ZELINSKY, W. (I97I). The Hypothesis of the Mobility Transition. Geographical Review, v.6I, n.2, p.219-249. 
